\title{
Intravitreal Medications for Retinal Vein Occlusion: Systematic Review and Meta-analysis
}

\author{
Alireza Lashay ${ }^{1}$, MD; Hamid Riazi-Esfahani ${ }^{1}$, MD; Masoud Mirghorbani ${ }^{1}$, MD, MPH; Mehdi Yaseri ${ }^{1,2}$, PhD \\ ${ }^{1}$ Translational Ophthalmology Research Center, Farabi Eye Hospital, Tehran University of Medical Sciences, Tehran, Iran \\ ${ }^{2}$ Department of Epidemiology and Biostatistics, Tehran University of Medical Sciences, Tehran, Iran \\ ORCID: \\ Alireza Lashay: https://orcid.org/0000-0002-6409-4654
}

\section{Abstract}

Purpose: To evaluate the outcomes of different intravitreal injections for the treatment of retinal vein occlusion including central retinal vein occlusion (CRVO) and branch retinal vein occlusion (BRVO).

Methods: PubMed, Cochrane, the metaRegister of ControlledTrials, and ClinicalTrials were searched for intravitreal anti-Vascular Endothelial Growth Factor (VEGF) and steroids with relevant keywords and date limitation of 2009-2018. Meta-analysis was performed on studies that met the defined inclusion criteria. Main outcomes were visual acuity (VA) and central macular thickness (CMT).

Results: Out of 681 studies, 36 articles (including 21 reporting CRVO and 15 dealing with BRVO) were selected for systematic review. All five intravitreal drugs including triamcinolone, dexamethasone, ranibizumab, bevacizumab, and aflibercept showed improvement of CMT and VA as compared to placebo or laser treatment. Six randomized controlled trials were selected for meta-analysis in RVO patients. The pooled mean difference of visual improvement between sham and ranibizumab was 12.7 Early Treatment for Diabetic Retinopathy Study (ETDRS) letters (95\% Cl: 11.00 to 13.2), and the pooled mean difference in CMT reduction was $221 \mu \mathrm{m}$ (95\% Cl: 153 to 284); both changes were significantly in favor of ranibizumab. The pooled mean difference of visual improvement between bevacizumab and triamcinolone was 5.3 ETDRS letters in favor of bevacizumab (95\%Cl: $16 \mu \mathrm{m}$ to $17.5 \mu \mathrm{m})$. Triamcinolone led to $68.1 \mu \mathrm{m}$ greater CMT reduction than bevacizumab (95\% Cl: $58 \mu \mathrm{m}$ to $76 \mu \mathrm{m}$ ). However, none of these differences were statistically significant. Conclusion: Treatment with anti-VEGF agents in RVO is superior to observation. No significant difference was seen between the eyes treated with bevacizumab or triamcinolone based on these results.

Keywords: Anti-vascular Endothelial Growth Factor; Dexamethasone; Retinal Vein Occlusion; Triamcinolone

J Ophthalmic Vis Res 2019; 14 (3): 336-365

\section{Correspondence to:}

Alireza Lashay, MD. Translational Ophthalmology Research Center, Farabi Eye Hospital, Tehran University of Medical Sciences, Qazvin Square, Tehran 13366, Iran. E-mail: Lashay3601@gmail.com

Received: 11-10-2018 Accepted: 29-04-2019

\begin{tabular}{|c|}
\hline Access this article online \\
\hline $\begin{array}{l}\text { Website: } \\
\text { https://knepublishing.com/index.php/JOVR }\end{array}$ \\
\hline $\begin{array}{l}\text { DOI: } \\
\text { 10.18502/jovr.v14i3.4791 }\end{array}$ \\
\hline
\end{tabular}

This is an open access journal, and articles are distributed under the terms of the Creative Commons Attribution-NonCommercial-ShareAlike 4.0 License, which allows others to remix, tweak, and build upon the work non-commercially, as long as appropriate credit is given and the new creations are licensed under the identical terms.
How to cite this article: Lashay A, Riazi-Esfahani $\mathrm{H}$, Mirghorbani M, Yaseri M. Intravitreal medications for retinal vein occlusion: Systematic review and meta-analysis. J Ophthalmic Vis Res 2019;14:336-365 


\section{INTRODUCTION}

Retinal vein occlusion (RVO) is caused by thromosis in central, hemi-central, or branch retinal veins. ${ }^{[1]}$ In central retinal vein occlusion (CRVO), the obstruction usually occurs at the level of the lamina cribrosa, while in branch retinal vein occlusion (BRVO), it involves a branch of the central retinal vein. ${ }^{[1-3]}$ The clinical manifestations of RVO is largely related to the secondary elevation of Vascular Endothelial Growth Factor (VEGF) levels in the vitreous and retina due to retinal ischemia. ${ }^{[1]}$ The following conditions have been variably reported as associations of RVOs: systemic hypertension, diabetes mellitus, hyperlipidemia, hyper-homocysteinemia, blood coagulation disorders, systemic inflammatory disorders, glaucoma, short axial length, and high body mass index. ${ }^{[2-6]}$ Two major consequences of RVO which lead to decreased visual acuity (VA) are macular edema (ME) and retinal ischemia. In eyes with nonischemic CRVO, VA improves significantly following resolution of ME. ${ }^{[4,6,7]}$ However, in the eyes with ischemic CRVO, no significant association has been found between the presence or absence of ME and improvement in VA due to permanent damage to macular ganglion cells. ${ }^{[7]}$ Other factors may also affect the natural history of CRVO. Demographic factors such as age or male gender, systemic factors including vascular risk factors or high levels of blood hematocrit, and ocular factors such as macular pigmentary change, epiretinalmembrane formation following long-standing ME, retinociliary collaterals, and glaucoma have been reported to be associated with poor functional outcomes. ${ }^{[8]}$ The development of anterior segment neovascularization also has a detrimental effect on visual outcomes. ${ }^{[7,8]}$ Based on the Branch Retinal Vein Occlusion Study (BVOS) study, the visual prognosis in BRVO is better than CRVO. ${ }^{[9]}$ Therefore, it is not surprising to observe relatively good outcomes in the control group of large randomized controlled trials (RCTs) such as the Study on the Efficacy and Safety of Ranibizumab Injection in Patients With Macular Edema Secondary to BRVO (BRAVO). Visual acuity improvement in eyes with macular BRVO is usually more marked than eyes with major BRVO ${ }^{[10]}$ Ischemic insult to macular ganglion cells, pigmentary degeneration, and development of epiretinal membrane may adversely affect the visual outcome in BRVO. ${ }^{[1]}$ Various treatments have been proposed for the management of RVO-related ME and many RCTs have been designed to compare these therapies and their long-term outcomes. The selection of the most efficacious therapy providing the best outcome in clinical practice necessitates ophthalmologists to be updated on the results of recent trials and adopt a comprehensive approach toward the patient. In the current study, we aim to provide an update on recent trials addressing the management of RVOrelated $\mathrm{ME}$, compare the outcomes of these trials, and perform a meta-analysis on studies with similar arms according to the pre-defined inclusion and exclusion criteria.

\section{METHODS}

This systematic review and meta-analysis complies with the Preferred Reporting Items for Systematic Reviews and Meta-analyses (PRISMA) - 2009 rules.

\section{Search Methods for Identifying the Studies}

Two investigators ( $\mathrm{HR}$ and $\mathrm{MM}$ ) participated in the literature search via PubMed, Cochrane, the metaRegister of ControlledTrials, and ClinicalTrials in English language with date limitation of 2009-2018. In the search strategy which was last conducted on March 21, 2018, we used the MeSH term "retinal vein occlusion" and the words "*RVO", "*vitreal", "*VEGF*", "bevacizumab", "Avastin", "ranibizumab", "Lucentis", "aflibercept", "Eylea", "triamcinolone", "implant", and "Ozurdex". It should be noted that we only searched for the most popular agents in clinical practice and not the miscellaneous drugs presented in the case reports or case series.

\section{Selection of Studies for Systematic Review}

All titles and abstracts were independently screened by two co-authors (HR and MM) and the potential relevance was judged. Any disagreement between the two authors was referred to the corresponding author (AL) for final decision. The final list of included studies was re-evaluated to ensure proper study selection. Only papers with full-texts or abstracts in English were selected. 


\section{Data Collection}

Data was collected separately by HR and MM from all included studies:

- First and corresponding authors, journal, year, main criteria for inclusion in the study, any exclusion criteria, number of eyes, treatment arms, and length of the study.

- Means and standard deviations of changes in corrected VA and central macular thickness (CMT) changes from baseline.

Each article was evaluated carefully and rated by the panel (HR, MM, and MY) according to the level of evidence provided by the study. The level of evidence was assigned to each study according to the latest guidelines of the British Centre for Evidence-Based Medicine; ${ }^{[12]}$

- Level I: well-conducted and designed randomized clinical trials

- Level II: lower-quality randomized, welldesigned case-control, and cohort studies

- Level III: lower-quality cohort and casecontrol studies and case series

\section{Outcome Measurement}

The mean change of VA from baseline was the primary outcome measure. The secondary outcomes included: (1) The proportion of patients gaining 15 Early Treatment for Diabetic Retinopathy Study (ETDRS) letters or more compared to baseline at different time points; (2) Mean change of CMT on optical coherence tomography (OCT) from baseline as the anatomical outcome measure.

\section{Meta-analysis: Inclusion and Exclusion Criteria}

Studies were included in the meta-analysis if they met the following criteria: (1) randomized controlled clinical trials with level I of evidence, (2) mean follow-up of six months or more, (3) comparing anti-VEGF or intravitreal corticosteroid with placebo or laser treatment for ME due to CRVO or BRVO, (4) providing the proportion that gained 15 ETDRS letters or more, (5) providing changes of VA and CMT in the treatment and sham groups for calculating mean difference (MD), odds ratio
(OR), and 95\% confidence interval (95\% Cl). Metaanalysis was performed on studies with level I evidence with comparable arms and methods. Studies were excluded from meta-analysis if they were retrospective, non-controlled, non-randomized, or were not in English. We chose six months as the minimum time point for meta-analysis. The mean change in VA and CMT was measured as a continuous variable and calculated as MD with $95 \%$ $\mathrm{Cl}$.

\section{Methodological Quality/Risk of Bias Assessment}

The methodological efficiency of studies was evaluated for the quality based on the modified Jadad scoring system. ${ }^{[13,14]}$ Through this assessment tool, we evaluated three main study characteristics including randomization, blinding, and participant dropout. Studies with Jadad score of three points or more were considered as high-quality studies. Also, a risk of bias summary was provided by each data collector separately including selection bias, detection bias, and attrition bias in order to assess various potential sources of systemic-bias.

\section{Heterogeneity Assessment}

Both clinical and methodological heterogeneities were assessed for meta-analysis. We considered 12 values more than $60 \%$ to indicate substantial statistical heterogeneity. The Random-effects model was used for meta-analysis.

\section{Statistical Analysis}

All analyses were performed using the Stata (StataCorp. 2013. Stata Statistical Software: Release 13. College Station,TX: StataCorp LP). The mean post value of the studied outcomes was extracted from each study. Using the forest plots, the 95\% confidence interval of the difference of treatments in each study and the pooled effect of all studies were demonstrated. Heterogeneity of studies was evaluated using Cochran's Q-test and I-square index. An I-square more than 0.70 or a P-value $<0.05$ was considered as the indication of heterogeneity. To compensate for the heterogeneity of the results of the studies, the Random-effects model was applied. The funnel plot (qualitative method) and Egger's regression test (quantitative 
method) were used for the evaluation of possible publication biases. Whenever the bias was present, the pooled mean value was adjusted using the trimming method.

\section{RESULTS}

The combined searches yielded 681 studies which decreased to 410 articles after the duplicates were removed. The panel reviewed 131 articles in full text based on the inclusion criteria. Of these, 36 articles (CRVO: 21 and BRVO: 15), 27 level Ior II-rated studies were selected for systematic review based on the compatibility with the inclusion criteria [Tables 1 and 2].

Studies with level I evidence and comparable arms and methods were chosen for meta-analysis. Meta-analysis was done on studies that compared the effectiveness of bevacizumab versus triamcinolone acetonide and ranibizumab versus sham. Due to the heterogeneity in the dosages of intravitreal steroid and follow-up periods, we were not able to perform a meta-analysis on all RCTs; six RCTs were selected for meta-analysis based on the inclusion and exclusion criteria [Figure 1].

\section{Medical Management in CRVO}

\section{Description of the Condition in CRVO}

Macular edema is one of the main causes of reduced VA in CRVO. It is presumed to be a result of the hypoxia-induced capillary permeability after vein occlusion and subsequent hemorrhage. ${ }^{[15]}$ The most popular treatment in CRVO is the intravitreal injection of an anti-VEGF, such as bevacizumab, ranibizumab, and aflibercept. However, intravitreal steroid injection may also be considered especially in areas without access to anti-VEGF agents. Intravitreal dexamethasone implant is another therapeutic choice for CRVO-induced ME (CRVO-ME), ${ }^{[16]}$ while other treatments such as fibrinolytic or anticoagulant agents, angiostatic agents, acetazolamide and isovolemic hemodilution, have not been approved. ${ }^{[17]}$ Some surgical options were also suggested including induced chorioretinal anastomosis, injection of a fibrinolytic agent by direct venous cannulation, and radial optic neurotomy; however, none of them has been proven effective in the treatment of
CRVO-ME. ${ }^{[17]}$ The summary of the interventional studies on the management of CRVO-ME with level I or II of evidence are presented in Table 1.

\section{Intravitreal Corticosteroids}

Triamcinolone. Intravitreal injection of steroids is effective in CRVO-ME by reducing the capillary permeability and inhibition of the VEGF expression. In contrast to anti-VEGF drugs with specific site of action, steroids suppress the expression of many cytokines. However, they may cause cataract and steroid-induced glaucoma. It should be noted that the effects of intravitreal triamcinolone may last up to nine months, depending on the dosage applied. ${ }^{[18-20]}$

Ip et $\left.a\right|^{[18]}$ reported the results of the Standard Care versus Corticosteroid for Retinal Vein Occlusion (SCORE) study that compared $1 \mathrm{mg}$ and 4 mg doses of preservative free intravitreal triamcinolone acetonide (IVT) with the observation for ME-associated VA loss in perfused CRVO. At fourmonth follow-up, the median reduction in CMT was more in the $4 \mathrm{mg}$ IVT group ( $\mathrm{P}<0.001)$. However, at 12-month follow-up, there was no difference in terms of CMT reduction and VA improvement between the two triamcinolone groups. IVT led to a reduction in ME with a moderate correlation with VA. They reported that there was a significantly higher percentage of patients requiring IOP-lowering medications and also higher rates of cataract development in the steroid groups, especially in the $4 \mathrm{mg}$ IVT group. Considering these efficacy and safety findings, $1 \mathrm{mg}$ IVT was recommended in the treatment of CRVO-ME. In this study, the interval between the last triamcinolone application and the end of the follow-up period varied. Hence, some eyes in the study groups might have been out of the effective phase of the triamcinolone injection at the evaluation time.

Ramezani et al ${ }^{[21]}$ evaluated the effects of multiple intravitreal bevacizumab (IVB) injections versus IVT in the treatment of 86 eyes with ME due to acute CRVO. It was interesting that the differences were statistically significant in patients with ischemic CRVO in favor of the IVB group. At all visits, mean IOP rise was significantly higher in the IVT group in comparison with the IVB group. As a result, they recommended repeated IVB injections, specifically in ischemic cases. 


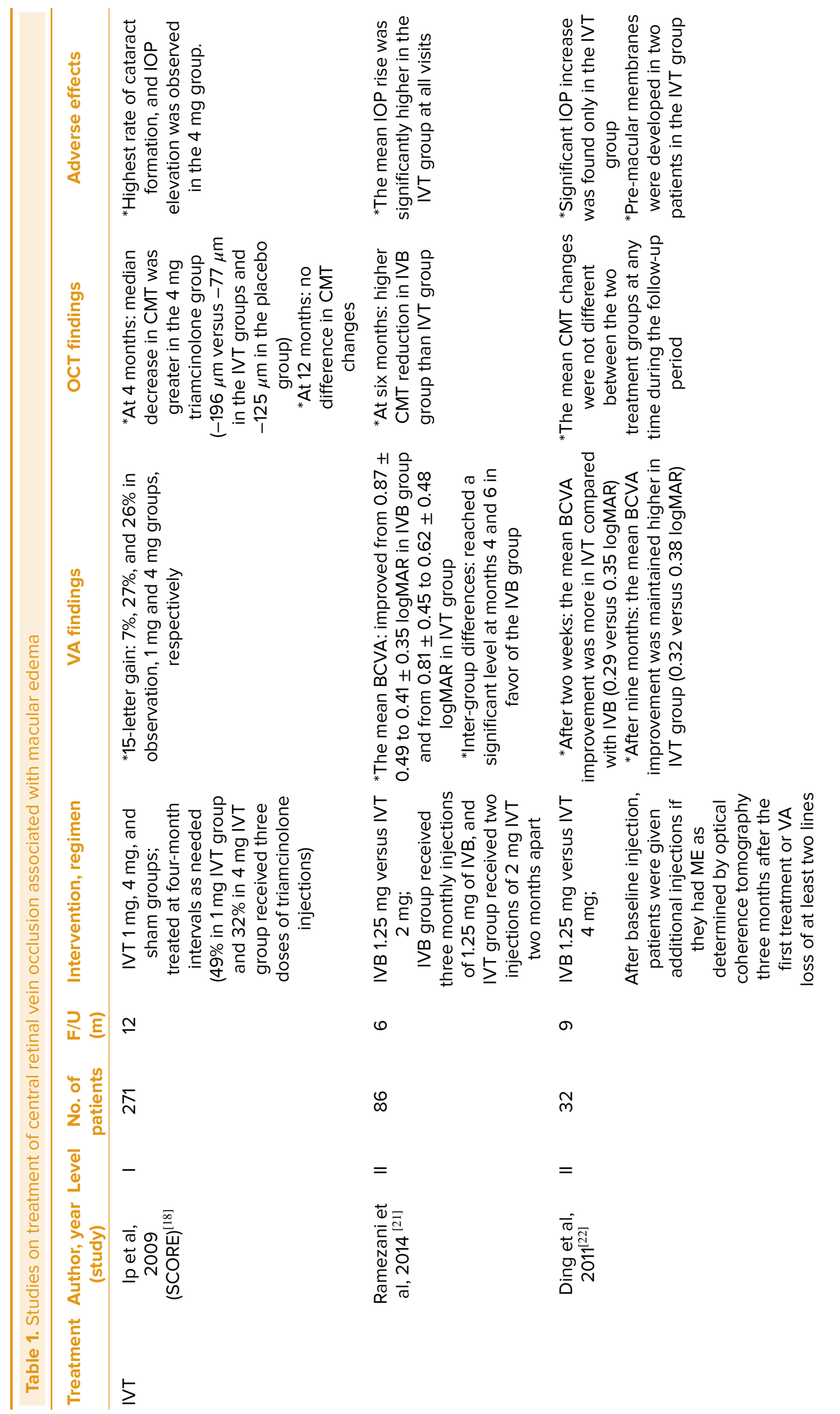




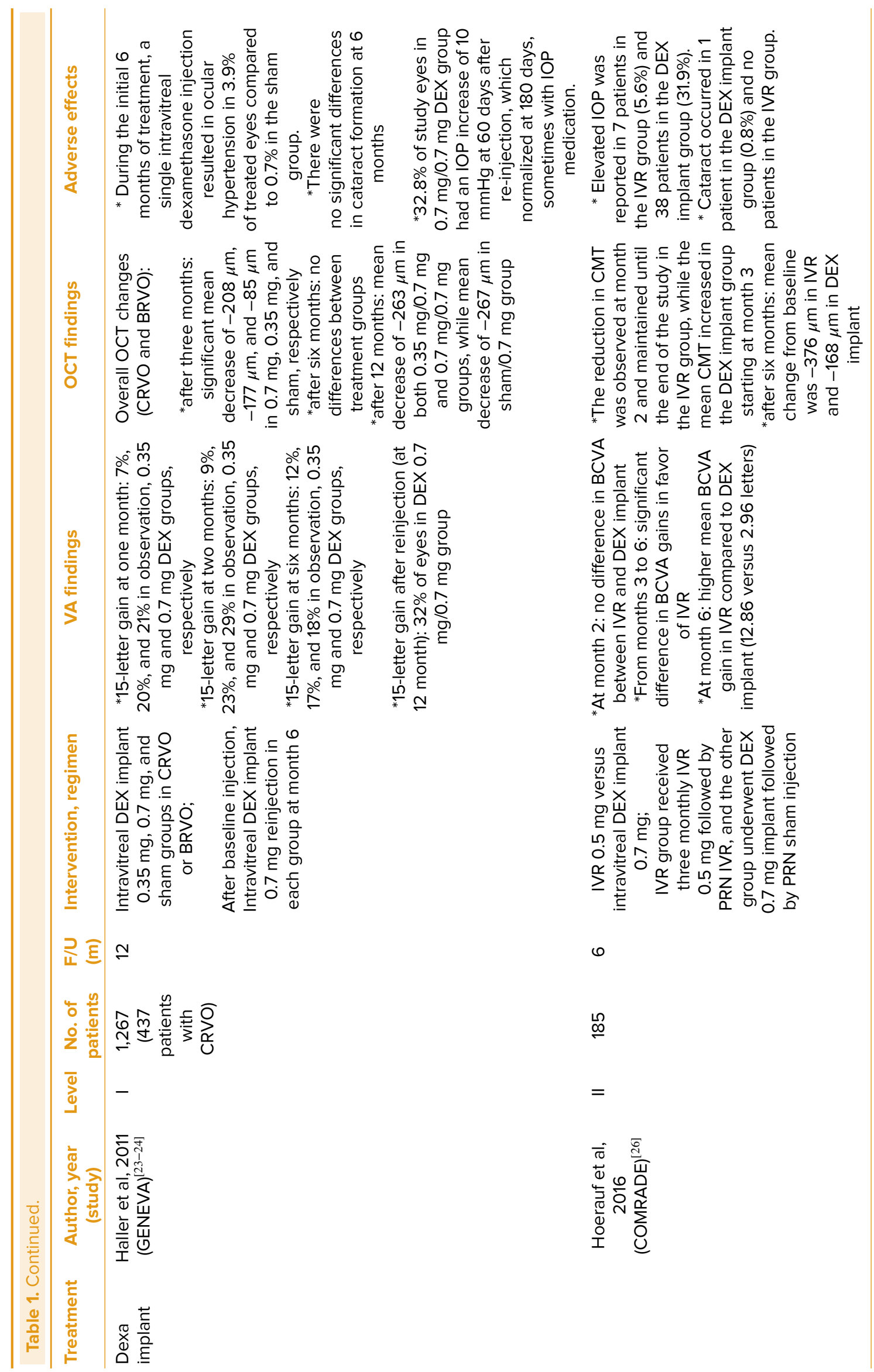




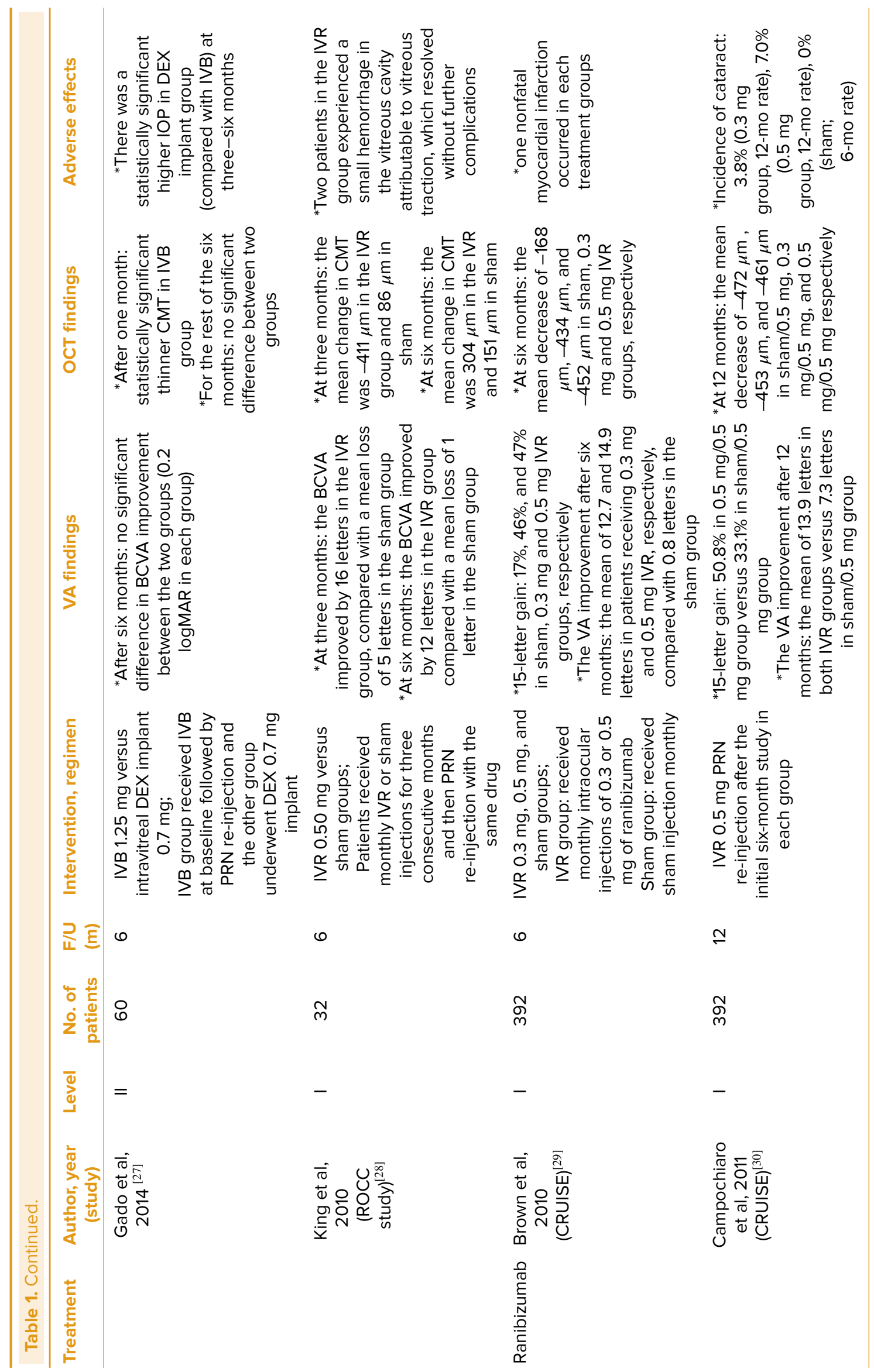




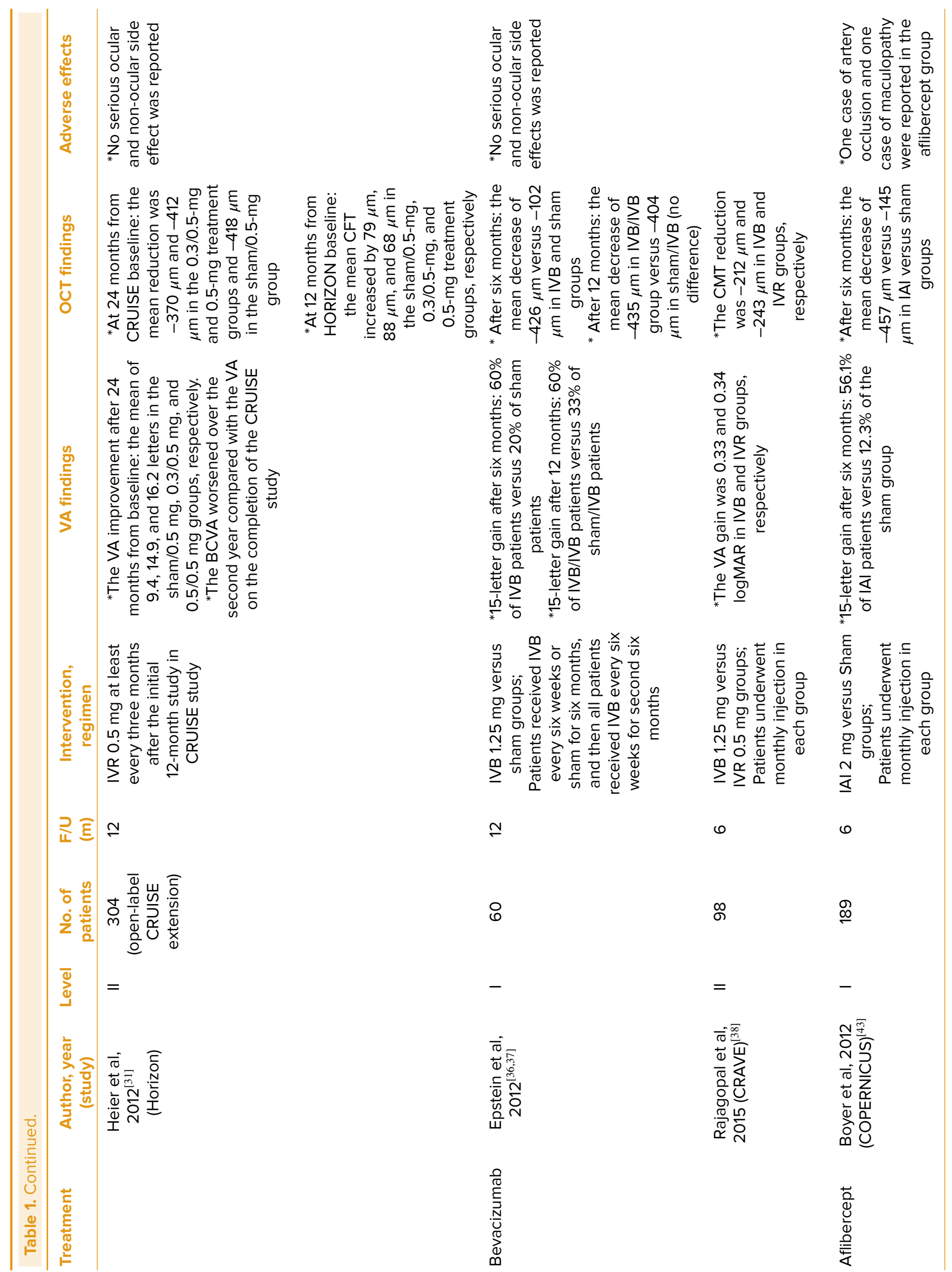




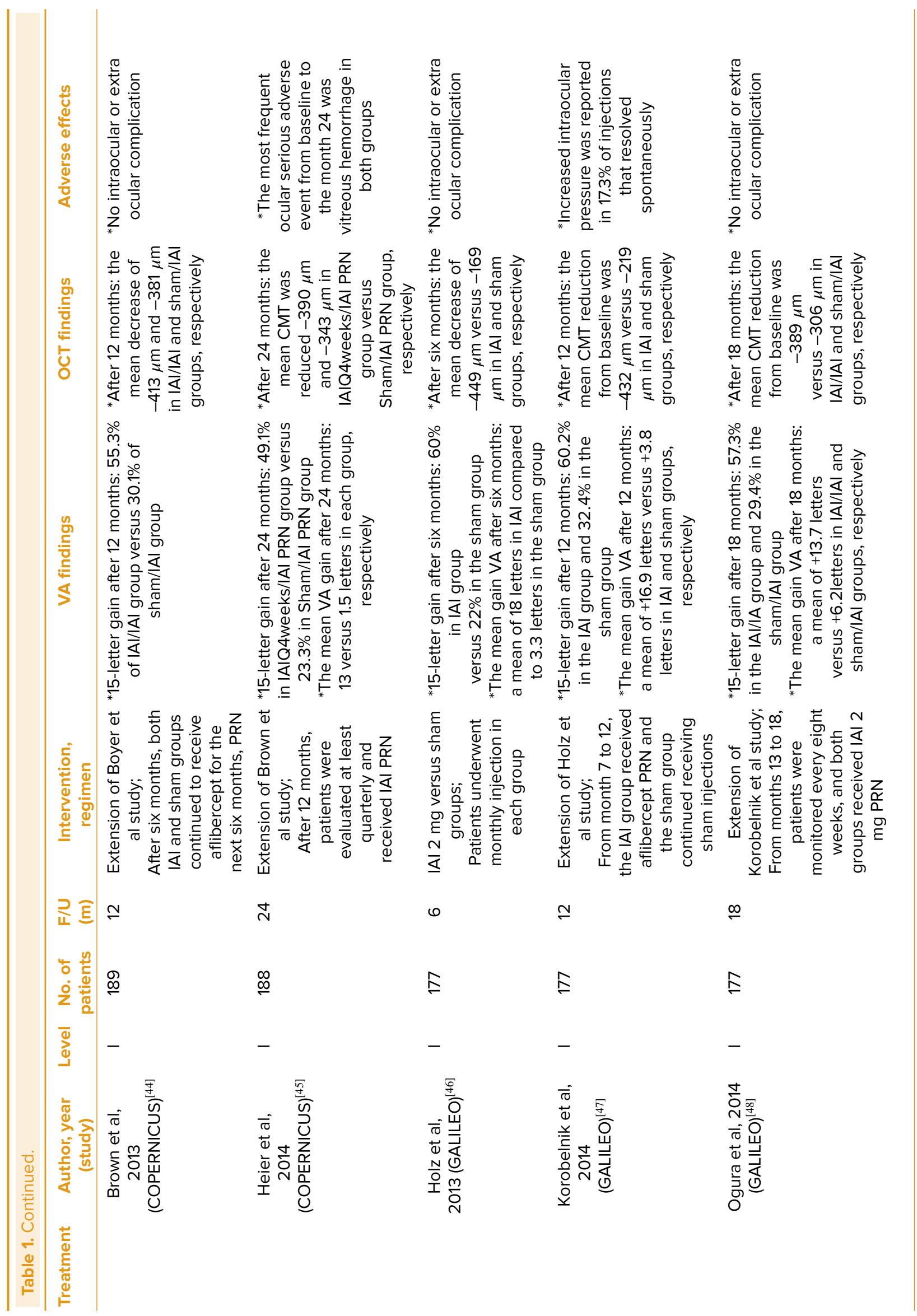




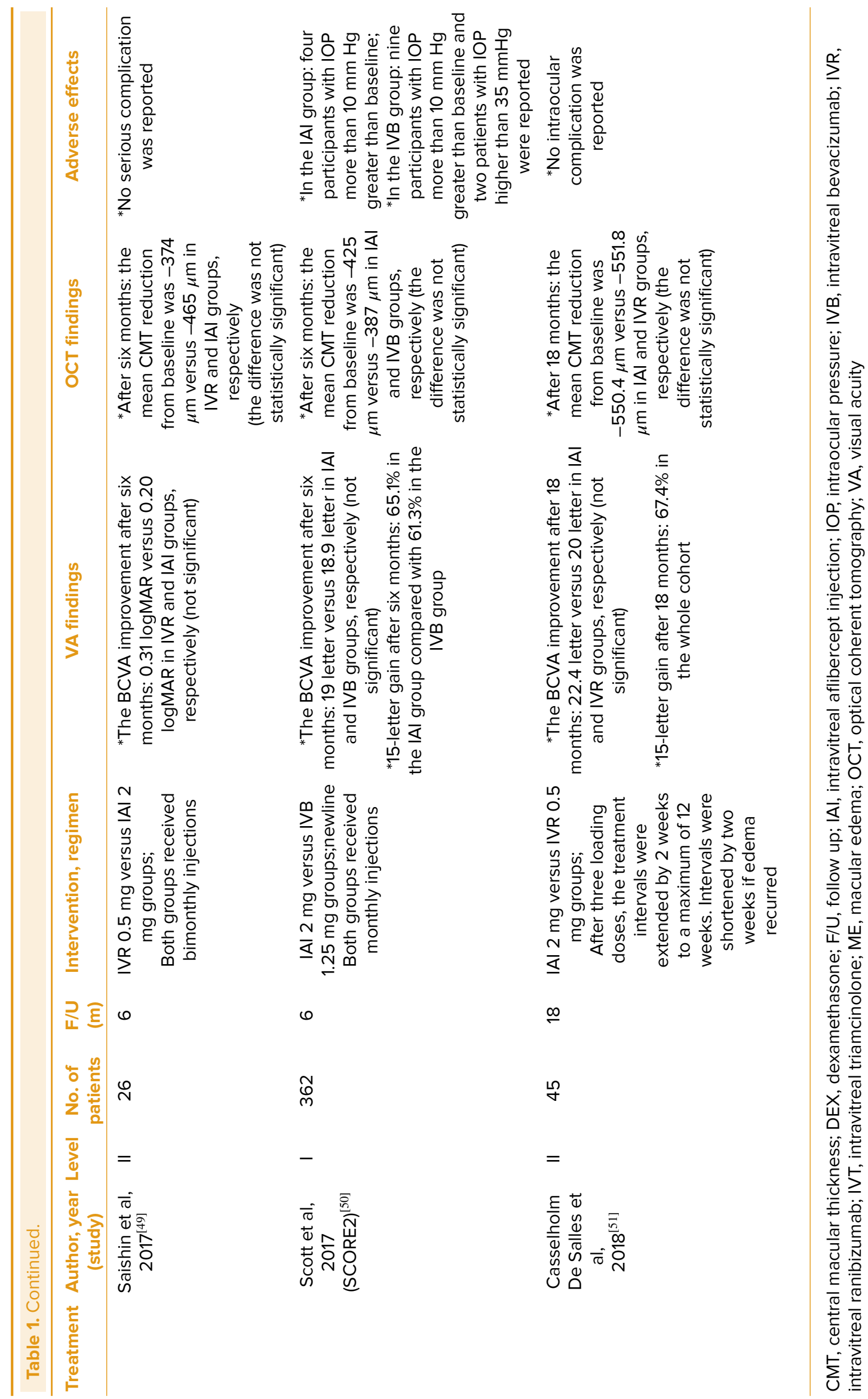




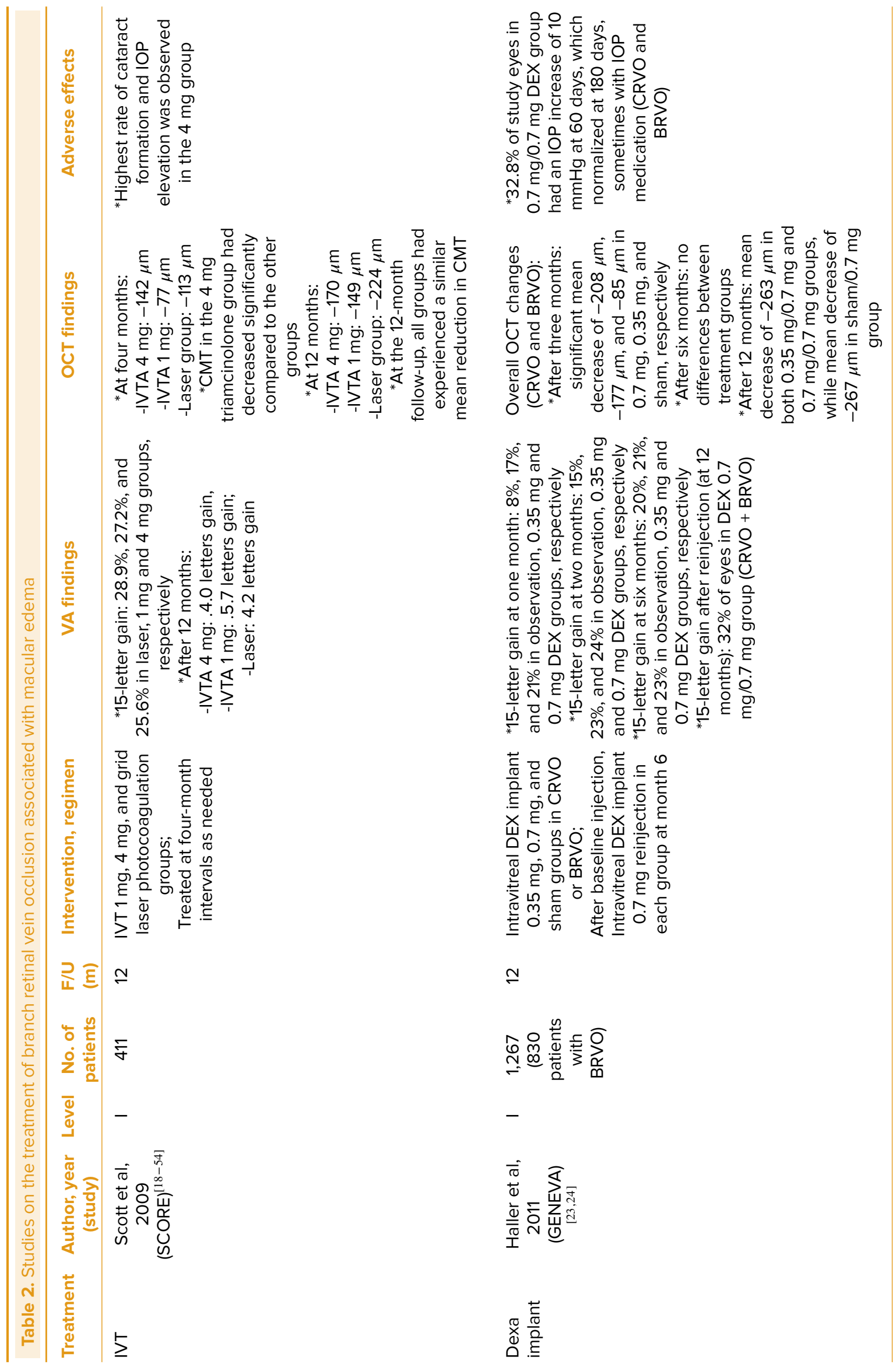




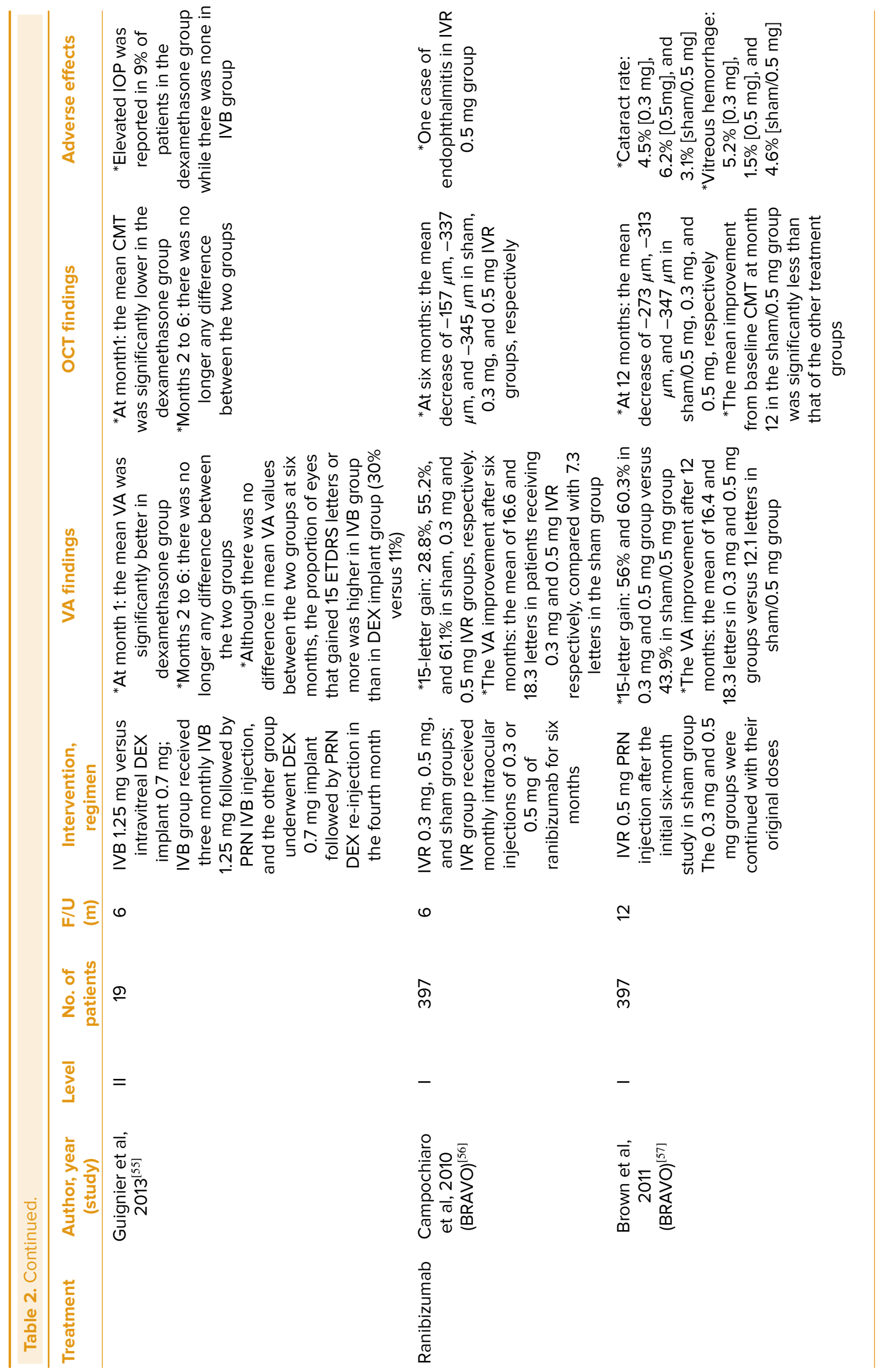




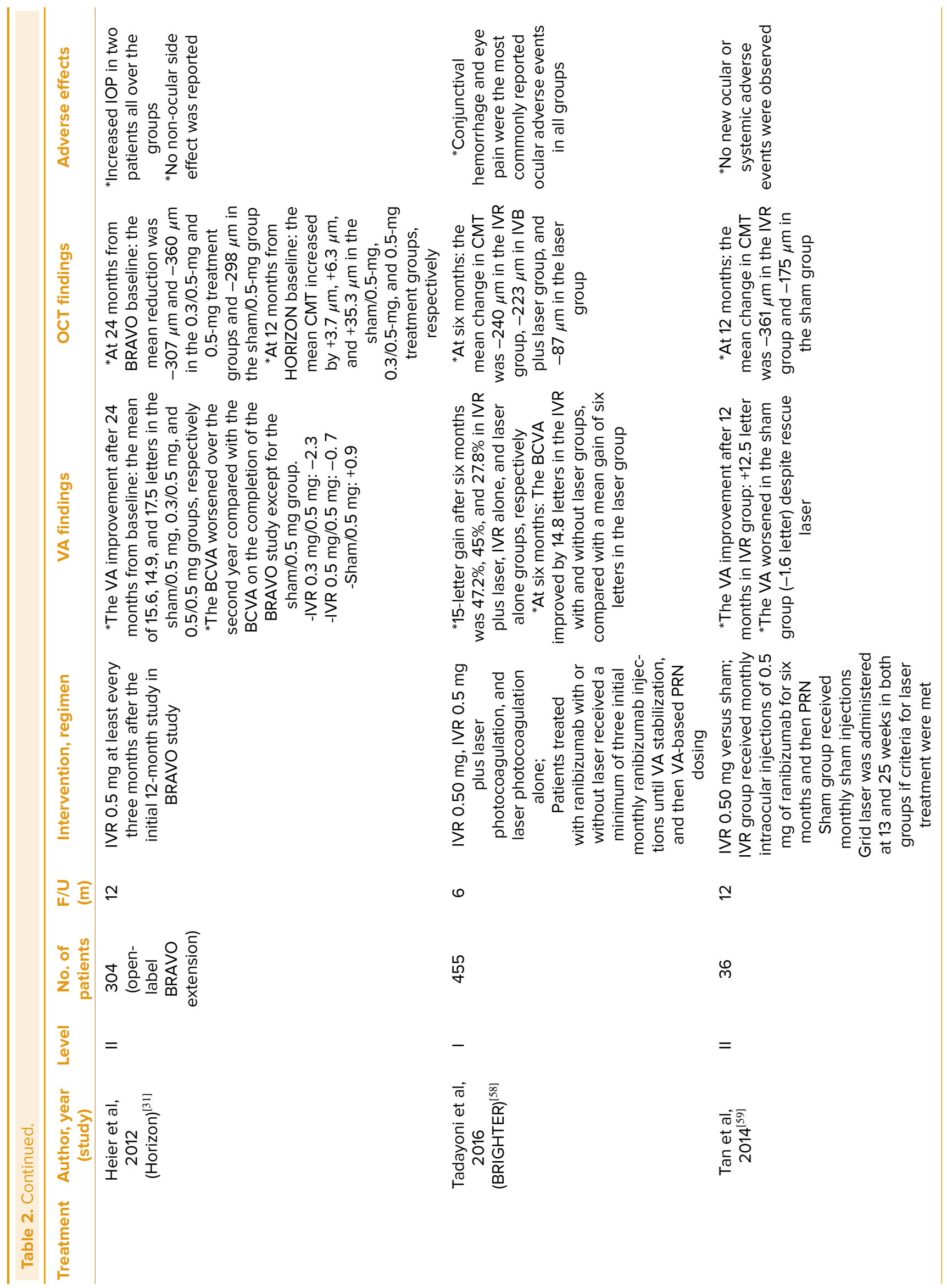




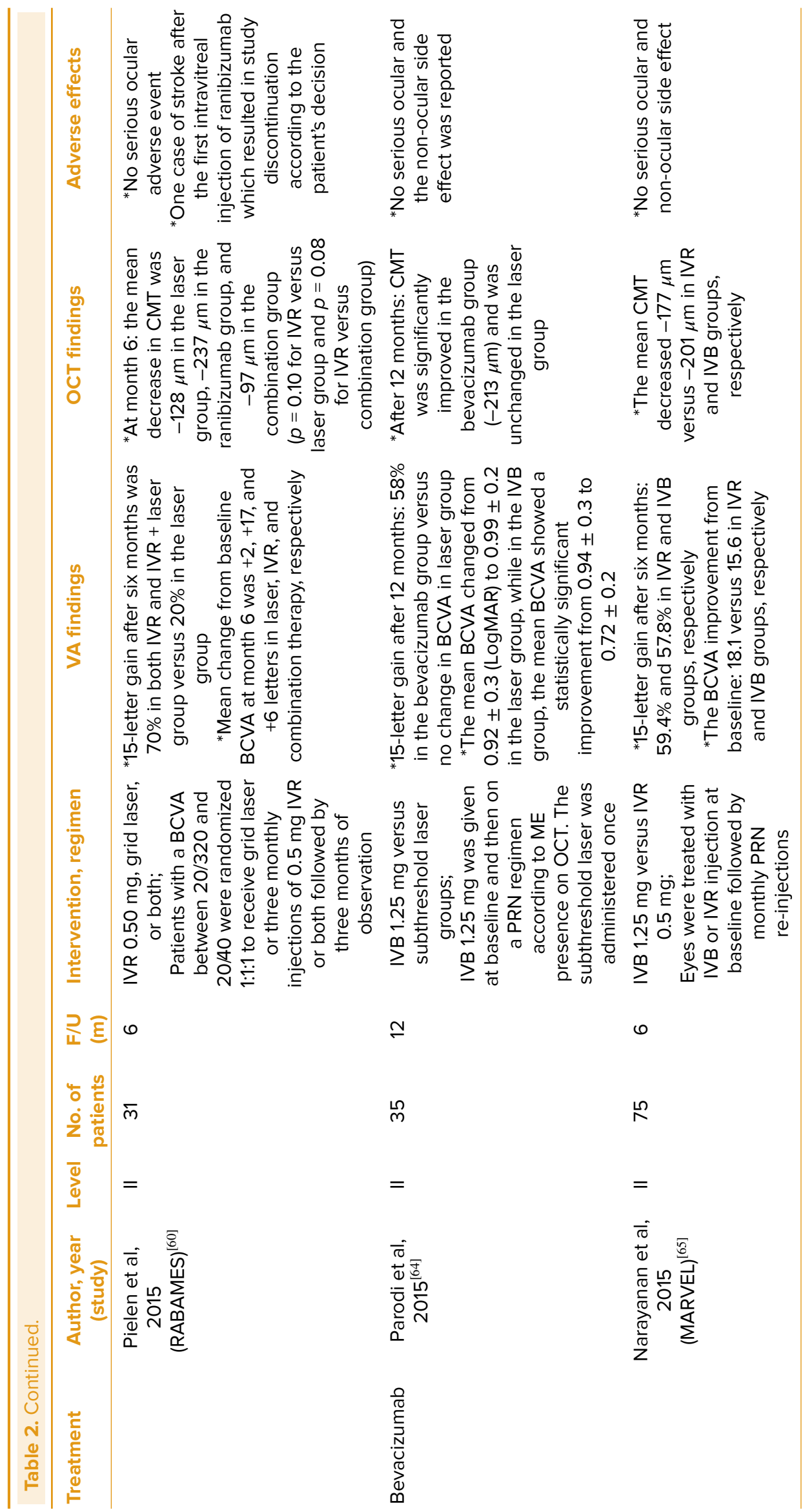




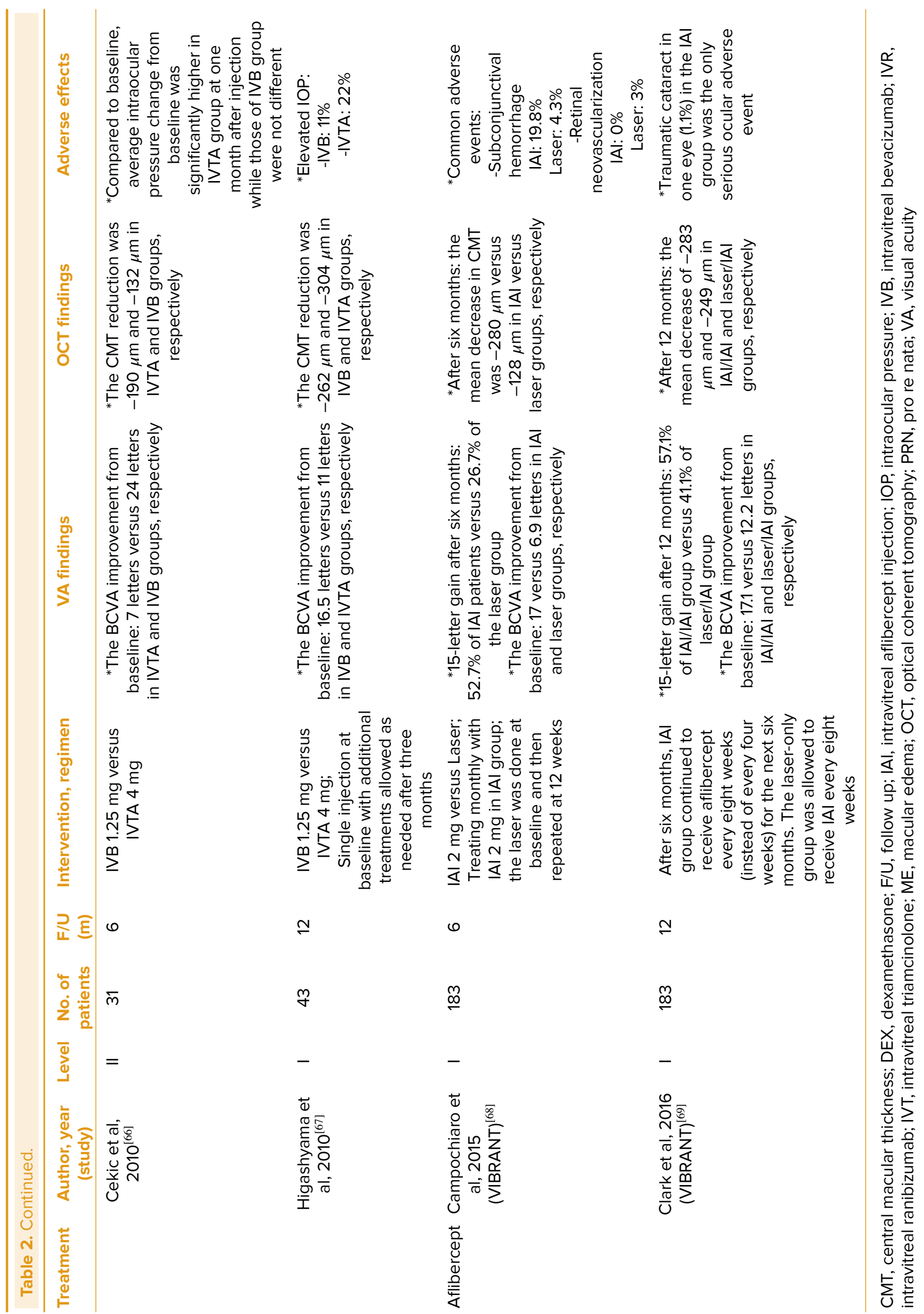




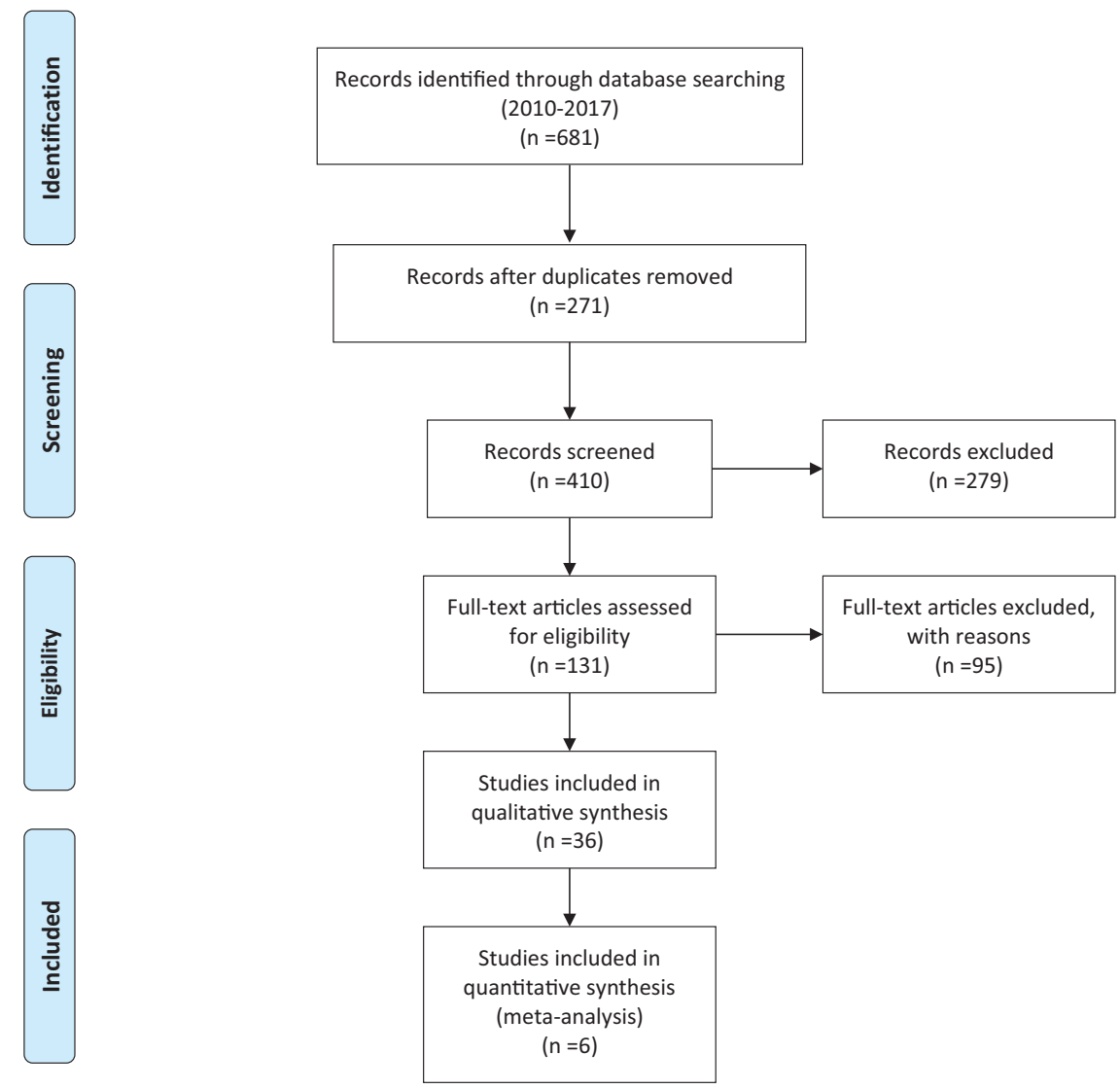

Figure 1. PRISMA flowchart.

Source: Moher D, Liberati A, Tetzlaff J, Altman DG, The PRISMA Group. Preferred reporting items for systematic reviews and meta-analyses: The PRISMA Statement. PLoS Med 6(7): e1000097. For more information, visit www.prisma-statement.org.

Ding et al ${ }^{[22]}$ compared the safety and efficacy of IVB and IVT in patients with CRVO. No statistically significant difference was found during the nine-month follow-up between the two treatment groups. Quicker visual recovery and improvement of CMT was observed in patients who underwent IVT injection compared with patients who received IVB. In addition, fewer injections were needed in the IVT group $(1.31 \pm 0.48)$ in comparison with the IVB group (2.38 \pm 1.04$)$. In this study, retreatment with IVB was performed three months after the first injection if persistent ME was observed, instead of three consecutive monthly injections in the first three months. Therefore, the IVB group might have been undertreated in this study.

Dexamethasone Intravitreal Implant (Ozurdex). Intravitreal dexamethasone implant is a slowrelease steroid in a biodegradable polymer form that lasts about three to four months. ${ }^{[23]}$ The results of the Global Evaluation of implantable Dexamethasone in Retinal Vein Occlusion with Macular Edema (GENEVA) trial were reported by Haller et al. ${ }^{[23]}$ They evaluated the efficacy and safety of intravitreal dexamethasone implant in two dosages compared with placebo injection in eyes with RVOME (either BRVO or CRVO). A total of 1,267 patients with VA between $20 / 50$ and 20/200 were enrolled. Patients with dexamethasone implant (either 0.35 $\mathrm{mg}$ or $0.70 \mathrm{mg}$ ) improved significantly faster compared to the placebo regimen. From the first month to the third month of treatment, more eyes in the dexamethasone implant group achieved 15 ETDRS letters compared to the placebo group $(P<0.001)$; the maximum response was observed at month 3. However, the proportion of eyes achieving 15 ETDRS letter improvement after six months was not different between the three groups. The mean VA improvement was more pronounced in the dexamethasone groups compared to the placebo group from month 1 to month $6(P=0.006)$; the greatest difference was observed at the end of the second month which was about seven ETDRS letters. The mean decrease in CMT was also marked significantly more in eyes receiving each 
dose of dexamethasone implant compared with placebo at month 3; however, the difference was not sustained up to month 6 . It seemed that these changes in CMT were parallel to changes in BCVA. The observed clinical efficacy of dexamethasone implant had a limited duration, lasting between 90 to 120 days with a gradual decline thereafter. However, the peak response was observed after three months and was accompanied with the highest incidence of IOP rise between days 60 to 90 . This study embraced a large proportion of non-ischemic CRVO patients that led to encouraging outcomes, but the use of dexamethasone in ischemic CRVO remained questionable. Visual acuity improvement was sustained after the extension of the GENEVA study to 12 months by repeated injections of dexamethasone implant. On the other hand, complications were observed more frequently with repeated doses of dexamethasone implant, but these side effects could be satisfactorily managed by either surgery or medications. After the second dexamethasone implant, a large number of patients were able to maintain the visual gain of more than 15 ETDRS letters beyond six months although more steroid-related complications might occur. ${ }^{[24]}$

In SOLO study (Functional and Anatomical Results after a Single Intravitreal Ozurdex Injection in Retinal Vein Occlusion), Bezatis et al evaluated the efficacy period of Ozurdex (dexamethasone implant) in both CRVO- and BRVO-related ME. Like Geneva study, this study showed that early reinjection of dexamethasone implant after 16 weeks instead of 24 weeks was required in most cases; $40.7 \%$ of the BRVO group and $15 \%$ of the CRVO group required reinjection after 17.5 and 17.6 weeks, respectively. ${ }^{[25]}$

Hoerauf et al in COMRADE C study (Clinical Efficacy and Safety of Ranibizumab Versus Dexamethasone for CRVO) evaluated the efficacy of dexamethasone implant versus ranibizumab in eyes with CRVO-ME. ${ }^{[26]}$ They showed that although both treatment groups had a similar outcome in the first two months, the efficacy of ranibizumab sustained throughout the study, while dexamethasone therapeutic effect decreased from month 3 onward. The limitation was that all eyes in the dexamethasone group were treated with only a single dosage during the six-month period of the study. Based on the GENEVA and SOLO studies, the effect of treatment gradually decreases after three months and re-injection is needed. In other words, in clinical practice, dexamethasone re-implantation might be required earlier than six months.

In a randomized clinical trial by Gado et al, the efficacy of intravitreal dexamethasone implant versus repeated bevacizumab injections were evaluated in six months. They showed that both drugs provided the same effect on VA gain and CMT reduction after the first six months of treatment although there was a significantly higher rate of IOP rise in the dexamethasone implant group compared with the IVB group at three-six months. ${ }^{[27]}$

\section{Anti-VEGF Agents}

Ranibizumab. ROCC study (a Randomized Study Comparing Ranibizumab to Sham in Patients with ME Secondary to CRVO) was performed to compare ranibizumab with placebo regimen in patients with CRVO-ME. At each time point, BCVA was improved in the ranibizumab group compared with the visual loss in the sham group ( $P=0.001$ ). Eighty percent of cases $(n=12)$ in the ranibizumab group required more than three initial injections $(4.3 \pm 0.9)$ during the study. They concluded that monthly ranibizumab injection significantly improved ME and BCVA; maintaining the initial improvement would be possible with consecutive repeated injections. ${ }^{[28]}$

Ranibizumab for the Treatment of Macular Edema after Central Retinal Vein Occlusion CRVO (CRUISE) trial compared the efficacy of ranibizumab $0.3 \mathrm{mg}$ or $0.5 \mathrm{mg}$ with placebo in CRVO-ME. ${ }^{[29]}$ After six months, the VA of patients treated with either $0.3 \mathrm{mg}$ or $0.5 \mathrm{mg}$ ranibizumab improved significantly more than the placebo group. Additionally, anatomical changes correlated well with the visual improvements. Later, Campochiaro et $\mathrm{al}^{[30]}$ published the 12-month results of the CRUISE trial. In this extension of the study, patients were eligible to be treated with $0.5 \mathrm{mg}$ ranibizumab on a pro re nata (PRN) basis if BCVA was less than 20/40 or CMT was more than $250 \mu \mathrm{m}$. The superiority regarding the mean ETDRS letter gain after one year was maintained in the ranibizumab treatment groups compared with the placebo group. After 12 months, the mean reduction of CMT was similar between the study groups. The number of needed injections was of interest as it determined the financial burden. The mean number of injections among all randomized patients was 3.3 to 3.8 at months 6 to 12 based on the PRN approach. As a 
result, ranibizumab was superior to sham based on the visual improvement at months 6 and 12, and the $0.5 \mathrm{mg}$ ranibizumab was a more effective regimen in the treatment of CRVO-ME, based on this study.

HORIZON trial (Ranibizumab for Macular Edema due to Retinal Vein Occlusions: Long-term Followup) provided data regarding ranibizumab use in 24 months and analyzed the long-term safety and efficacy of ranibizumab in RVO-related ME (either BRVO or CRVO). ${ }^{[31]}$ It was a multicenter singlearmed study with 304 patients from the BRAVO and 304 patients from the CRUISE studies being recruited. They were evaluated at three-month intervals and were candidates for $0.5 \mathrm{mg}$ intravitreal ranibizumab if the recurrence of $M E$ or a drop in VA was identified. Indeed, HORIZON was an extension study of the BRAVO and CRUISE studies. In the second year, fewer ranibizumab injections in patients with CRVO was associated with a more prominent worsening of visual outcomes compared to the BRVO patients. A reasonable explanation is that retinal ischemia is more extensive in CRVO, leading to a larger VEGF drive that requires more frequent doses of ranibizumab injections. Hence, fewer ranibizumab injections and reduced followup in the second year of treatment resulted in a decline in VA of CRVO patients.

A post-hoc analysis study based on the data obtained by BRAVO and CRUISE trials evaluated the effects of ranibizumab on RVO-related ME (789 patients: BRAVO, $n=397$; CRUISE, $n=392$ ). VA improvement was observed just after seven days post-injection and was persistent up to 12 months by the PRN regimen. The time to first gain of 15 ETDRS letters of VA in the CRVO group was 4 months and in the BRVO group was 5.2 months after repeated $0.5 \mathrm{mg}$ monthly ranibizumab injections. Overall, more than half of the patients who received monthly regimen achieved significant functional improvement after the first six months of the treatment. ${ }^{[32]}$

Bevacizumab. Several retrospective and prospective studies reported the efficacy of intravitreal injection of bevacizumab in the improvement of VA and reduction of CMT. [22, 33-35] In a prospective controlled clinical trial by Epstein et $\mathrm{al}^{\left[{ }^{[36]}\right.}$ after six months, three times more patients in the study group had gained at least 15 letters than the sham group. The mean CMT reduction was significantly more pronounced in the bevacizumab group compared to the control group. The authors continued the study with a six-month extension period. ${ }^{[37]}$ From 6 months to 12 months, all patients from both groups were candidates to be treated with PRN bevacizumab every six weeks. CMT reduction was prominent in both sham/bevacizumab and bevacizumab/bevacizumab groups. However, vision improvement was more prominent in the bevacizumab/bevacizumab group versus the sham/bevacizumab group. Although anatomic improvement occurred after crossing over of sham patients to bevacizumab, functional improvement was limited. Therefore, earlier treatment might lead to better outcomes.

Rajacopare et al in CRAVE study (Bevacizumab Versus Ranibizumab in the Treatment of Macular Edema Due to Retinal Vein Occlusion) ${ }^{[38]}$ compared the efficacy of monthly ranibizumab or bevacizumab for RVO-ME in a randomized clinical trial. After six months, changes in CMT and VA were not different between the treatment groups. Although the efficacy of bevacizumab and ranibizumab are reported to be quite similar in the treatment of CRVO-ME in many studies, ${ }^{[39-41]}$ the use of bevacizumab in the management of RVO-ME remains off-label.

Ding et al ${ }^{[22]}$ evaluated the safety and efficacy of IVT versus IVB for CRVO-ME. After nine months, 5 of the 16 IVT eyes and 12 of the 16 IVB eyes needed re-treatment. The mean number of injections in the triamcinolone group (1.3) was less than in the bevacizumab group (2.4). BCVA improvement occurred at all time points after the injections in both study groups, and no significant difference was observed between the two groups.

Some non-randomized studies reported more chance for vision gain in eyes treated with a combination of dexamethasone and IVB than eyes that received dexamethasone implant monotherapy ${ }^{[42]}$.

Aflibercept. The protein VEGF Trap-Eye (aflibercept) comprises key domains of human VEGF receptors 1 and 2, fused with human IgG FC fragment. Indeed, all isoforms of VEGF-A and placental growth factor would be blocked by this protein. The main advantage of aflibercept is its longer duration of activity. ${ }^{[43]}$ Hence, it may reduce the dosing intervals of intravitreal injections in comparison with ranibizumab and bevacizumab. GALILEO (General Assessment Limiting Infiltration of Exudates in Central Retinal Vein Occlusion with VEGF Trap-Eye) and COPERNICUS (Vascular 
Endothelial Growth Factor [VEGF] Trap-Eye: Investigation of Efficacy and Safety in Central Retinal Vein Occlusion) are multicenter randomized clinical studies that evaluated the intravitreal aflibercept effects in patients with CRVO-ME. ${ }^{[43-48]}$

In COPERNICUS study, ${ }^{[43]}$ VA improvement and macular thickness reduction after six months were significantly more in the aflibercept treated eyes than the control group. They also reported that reduced ocular neovascularization was noted in the aflibercept group. Later, Brown et al ${ }^{[44]}$ reported the 12-month results of COPERNICUS study in which the previously established arms for the RCT were eligible to be treated with PRN doses of aflibercept $2 \mathrm{mg}$ every four weeks from month 7 to month 12. After 12 months, the mean VA improvement was 16.2 and 3.8 letters in the aflibercept + PRN group and the sham + PRN group, respectively. They concluded that fewer injections of aflibercept after the loading period could maintain the VA gain; however, a delay in the treatment of ME could lead to irreversible damage due to chronic edema and disintegrated retinal layers. Heier et $\mathrm{al}^{[45]}$ reported the 24-month results of the study. After the first year, based on the study protocol, patients were evaluated every three months and were treated with aflibercept if needed. The visual gain was significantly more in the aflibercept/PRN group than the sham/PRN group after two years (13 versus 1.5 letters in each group, respectively). The mean number of PRN injections was less in the aflibercept + PRN (2.7 $\pm 1.7)$ compared with the sham + PRN (3.9 \pm 2.0$)$ during months 7 to 12 , while during months 13 to 24 the number of PRN injections were $3.3 \pm$ 2.1 versus $2.9 \pm 2.0$ in the two groups, respectively. They also showed that the functional and anatomic improvements, after fixed dosing through six months, followed by PRN regimen and monthly monitoring from months 7 to 12 , were reduced after continued PRN regimen and a reduced monitoring frequency from months 12 to 24 [Table 1]. They suggested a beneficial effect of anti-VEGF treatment in either group of patients with ischemic or nonischemic CRVO; this effect was significantly lower if treatment was started with a delay in both subgroups. Considering the time between diagnosis and treatment, they reported that the proportion of patients with 15 letter gain or more after six months was significantly more in patients who received the first intravitreal aflibercept injection during the first two months of diagnosis. They also showed that aflibercept is beneficial even in patients with poorpresenting VA of less than 20/200.

In a similar double masked RCT named GALILEO, patients with CRVO were randomized to intravitreal aflibercept $2 \mathrm{mg}$ or placebo monthly for six months. Based on GALILEO reports, the mean change in BCVA and CMT were more marked in patients receiving aflibercept than the sham group at week $24(P=0.0001) .{ }^{[6]}$ From months 7 to 12 , patients were monitored monthly; the aflibercept group was treated with the intravitreal drug on a PRN basis, and the placebo group continued to receive sham. From months 13 to 18, patients were monitored bimonthly, and both groups were treated with intravitreal aflibercept PRN. This study showed that the functional and anatomic improvements after fixed monthly dosing in the first six months were largely sustained even with the extension of the treatment intervals. Patients with a baseline BCVA of 20/200 or worse had a greater visual improvement after 12 months compared to patients with a baseline BCVA of better than 20/200. Similar to COPERNICUS study, this study revealed that, although delayed treatment with aflibercept led to anatomic improvement, the functional improvement was limited, and the effect could persist for two years. It showed that more improvement of vision might occur if treatment was started earlier. $^{[47,48]}$

Based on these studies, significant visual and anatomic improvements occurred in the first six months with fixed monthly aflibercept injections. These improvements were largely maintained by PRN aflibercept injection with a mean of 2.5 to 2.7 injections in the next six months. Therefore, a monthly loading dose for up to three months followed by bimonthly aflibercept may have similar efficacy to that of monthly ranibizumab. ${ }^{[47,48]}$

The efficacy of bimonthly intravitreal aflibercept and ranibizumab in CRVO-ME was evaluated by Saishin et al. They concluded that although no significant difference was observed in visual improvement between the two groups, VEGF may not be completely neutralized by bimonthly injections of ranibizumab in all patients with CRVO, which may lead to the recurrence of ME. ${ }^{[49]}$

Recently, in SCORE II study, the efficacy of monthly bevacizumab was compared with monthly aflibercept in patients with CRVO-ME. Based on this study, monthly bevacizumab was not inferior to 
aflibercept regarding visual improvement after six months. SCORE II extension studies probably will compare outcomes of these anti-VEGF agents after six months, using regimens other than monthly dosing. ${ }^{[50]}$

In a recent report of a randomized clinical trial, the injection frequency of aflibercept and ranibizumab in the treatment of CRVO-ME was investigated. Patients were allocated to receive either intravitreal aflibercept $(2 \mathrm{mg})$ or ranibizumab $(0.5 \mathrm{mg})$ in a treat and extent regimen. After 18 months, the number of injections was significantly lower in the aflibercept group (10.9) compared to the ranibizumab group (14.4) $(p=0.001)$. The mean treatment interval was significantly longer in the aflibercept group compared with the ranibizumab group (10.0 versus 6.6 weeks) $(p=0.001)$. The mean changes in BCVA and CMT were similar between the groups. The authors concluded that the application of treat and extent regimen with aflibercept in eyes with CRVO might reduce the treatment burden and, to some extent, the need for close monitoring of patients. ${ }^{[51]}$

\section{Medical Management of BRVO}

Similar to CRVO, ME is the main reason for visual loss in BRVO. Based on the Branch Vein Occlusion Study (BVOS), macular grid laser photocoagulation was an effective treatment in branch retinal vein occlusion-related macular edema (BRVO-ME). ${ }^{[9]}$ Pharmacologic intervention started with the use of corticosteroids: triamcinolone and dexamethasone. Multiple formulations of IVT were used as an off-label drug in the treatment of BRVO-ME. The intravitreal dexamethasone sustained-release implant was approved in $\mathbf{2 0 0 9}$ for the treatment of BRVO-ME by the U.S. Food and Drug Administration (FDA). ${ }^{[23,24]}$

In recent years, anti-VEGF agents (ranibizumab, aflibercept, and bevacizumab) have become the most popular therapeutics for BRVO-ME. In addition, other modalities have been evaluated in the treatment of BRVO including chorioretinal anastomosis with laser, separation of the common adventitia of the crossing artery and vein with removing the cortical vitreous following pars plana vitrectomy, and intra-vascular injection of t-PA through cannulation of the veins. ${ }^{[52,53]}$ Interventional studies on the management of BRVO-ME with levels I or II of evidence are summarized in Table 2.

\section{Intravitreal Corticosteroids}

Triamcinolone. In a study designed for the treatment of BRVO-ME, Scott et al compared the effectiveness of standard care (grid laser photocoagulation) versus corticosteroid for retinal vein occlusion (SCORE) study report $6 .^{[54]}$ This study was conducted to evaluate the efficacy of two doses of preservative-free intravitreal triamcinolone with grid photocoagulation in BRVO-ME patients with BCVA between 20/40 and 20/400 and CMT of more than $250 \mu \mathrm{m}$. At month 12, the VA improvement was similar between the groups; however, more complications were observed with $4 \mathrm{mg}$ triamcinolone (35\% with cataract progression and $41 \%$ with the need for IOP-lowering medications). During the first year, none of the treated eyes required glaucoma surgery. However, after 24 months, two eyes in the $4 \mathrm{mg}$ IVT group required surgical interventions. SCORE concluded that the therapeutic efficacy was quite similar in two groups although the $4 \mathrm{mg}$ triamcinolone might lead to more adverse effects.

\section{Dexamethasone Intravitreal Implant (Ozurdex)}

In the GENEVA study, 830 patients from a total of 1,267 patients $(66 \%)$ with RVO, who had a BRVO for at least six weeks, were randomized to receive dexamethasone implant $0.7 \mathrm{mg}, 0.35 \mathrm{mg}$, or placebo. Eyes with a history of laser photocoagulation were not excluded in this study. Visual improvement of 15 letters or more was achieved faster in both dexamethasone implant groups than the placebo group ( $P<0.001$ ). In addition, the percentage of eyes with sustained VA improvement was higher in the dexamethasone implant groups compared to the sham group after the third month $(P<0.001)$. The therapeutic effect of these implants was not sustained after six months. However, from months 1 to 6 , the overall mean increase in VA from baseline was significantly higher in the dexamethasone implant groups compared with the placebo group. In eyes with BRVO-ME with a duration less than 90 days, even greater functional improvement might be achieved with dexamethasone implants comparing to eyes with ME lasting more than three months based on the subgroup post-hoc analysis. The study did not mention CMT in each BRVO subgroups, but overall (i.e., combined CRVO 
and BRVO) a significant reduction in CMT was seen in both implant groups compared with the sham group in the first three months. However, after six months, anatomical changes did not differ significantly between the groups. ${ }^{[24]}$

Two years later, Guignier et al compared the dexamethasone implant with three monthly IVB injections in the treatment of BRVO-ME. The mean visual gain and CMT reduction was significantly more pronounced at the one-month visit in the intravitreal dexamethasone implant group which was compatible with a faster visual improvement. However, no difference was observed between the two groups at months 3,4, and 6. Despite no difference in mean VA between the study groups at month 6 , a significantly higher proportion of eyes treated with bevacizumab gained 15 letters or more compared with the dexamethasone group. More reinjections at month 4 were needed with the dexamethasone implant compared with the IVB treatment. $^{[55]}$

\section{Anti-VEGF Agents}

Ranibizumab. Campochiaro et al ${ }^{[56]}$ published the results of phase III of BRAVO study that compared two ranibizumab doses of $0.3 \mathrm{mg}$ and $0.5 \mathrm{mg}$ with placebo in BRVO-ME. In cases of progressive refractory edema at month 3 , rescue grid laser was done. After six months, the BCVA improvement and CMT reduction were higher in both ranibizumab groups compared with the placebo $(P<0.0001) .{ }^{[57]}$ After six months of initial monthly dosing, patients were switched to a PRN injections; $0.5 \mathrm{mg}$ of ranibizumab was injected in the placebo group, while the $0.3 \mathrm{mg}$ and $0.5 \mathrm{mg}$ groups were treated with their original doses. BCVA improvement at six months was maintained in the ranibizumab groups after one year. After starting ranibizumab in the sham group, vision improved; however, this improvement was less than the visual gain in the ranibizumab groups $(P<0.01)$. The mean CMT change was higher in the $0.3 \mathrm{mg}$ and $0.5 \mathrm{mg}$ groups compared to the sham group $(P<0.05)$ at six months.

HORIZON study ${ }^{[31]}$ was a two-year extension trial of the BRAVO and CRUISE studies. In the BRVO arm of the study, 304 patients were given evaluation at three-month intervals and were candidates for $0.5 \mathrm{mg}$ ranibizumab if recurrence of ME or a drop in VA was identified. HORIZON study was not completed and led to the variable follow-up periods among the study patients; about $63 \%$ of patients $(n=205)$ from BRAVO trial completed the period of 12 months in the HORIZON study. The mean number of injections in each of the previous BRAVO groups ranged from 2.0 to 2.4 during 12 months of the trial. Visual acuities were significantly increased compared with the BRAVO baseline BCVA in each treatment group. However, considering the baseline values of the HORIZON study, no change or even slight decline in VA was observed in the second year. The study suggested that maximal VA improvement that can be achieved by monthly injections may decline slowly with decreased follow-up visits.

Comparison of $0.5 \mathrm{mg}$ ranibizumab with or without adjunctive macular laser therapy, and laser therapy alone was done by Tadayoni et al. ${ }^{[58]}$ Three monthly intravitreal ranibizumab injections were performed in the ranibizumab groups and subjects were subsequently re-treated PRN according to the designed protocol. At six months, both ranibizumab groups showed significant visual improvement compared to the laser only group ( $P<0.0001$ ). There was no difference in the number of injections between the two ranibizumab groups. Anatomically, the mean CMT reduction at six months was significantly more in the ranibizumab groups than the laser group $(P<0.0001)$.

ITan et al $^{[59]}$ compared intravitreal $0.5 \mathrm{mg}$ ranibizumab with grid laser in BRVO-ME over one year. At the fourth and sixth months, more patients in the grid laser group (68.4\% and 50.0\%) received additional grid laser compared with the ranibizumab group (6.7\% and $8.3 \%)$. They concluded that significant and sustained functional and anatomic improvements were provided by the intravitreal ranibizumab in eyes with BRVO-ME.

In the Ranibizumab for Branch Retinal Vein Occlusion Associated Macular Edema Study (RABAMES), patients with BRVO-ME were randomized to treatment with three monthly intravitreal $0.5 \mathrm{mg}$ ranibizumab injections or grid laser or both 60 . The mean BCVA improvement after six months was significantly higher in the ranibizumab group compared to the other groups. The combination group required fewer laser retreatments at month 2 compared with the grid laser group (20\% versus $70 \%$ ). They concluded that ranibizumab might be more efficient in visual improvement compared to grid 
laser photocoagulation. Laser combined with ranibizumab neither augmented VA gain and macular thickness reduction nor did it prevent recurrence of ME. CMT increased gradually after stopping the injections in ranibizumab groups, while visual improvement was sustained, indicating that functional deterioration may occur after the structural disintegrities. Reinjection of ranibizumab after the initial loading dosage, even with a proper response to treatment, may be necessary based on the visual and anatomical changes.

Bevacizumab. Multiple studies ${ }^{[61-63]}$ evaluated the efficacy of bevacizumab in BRVO-ME although most of them are retrospective or with small sample size. Based on a prospective study by Russo et al, ${ }^{[63]} 30$ eyes with BRVO were randomized to treatment with monthly IVB or macular grid laser over 12 months. At all time-points of the study, more improvement in BCVA and CMT was observed in the bevacizumab group than the laser group $(\mathrm{P}<$ 0.005).

In a prospective randomized interventional study, ${ }^{[64]}$ PRN IVB and subthreshold grid laser were compared as second line therapy for ME in BRVO. This study showed better anatomic and functional results in the IVB group compared to the subthreshold grid laser group.

In a prospective randomized clinical trial by MARVEL group, the efficacy of IVB and ranibizumab (IVR) in BRVO-ME was compared. The number of injections was not significantly different between the treatment groups $(3.2 \pm 1.5$ versus $3.0 \pm 1.4$, respectively; $P=0.55)$. There was a significant improvement in VA and CMT in eyes that underwent either bevacizumab or ranibizumab injection without any significant difference between the two drugs. [65]

In one study, patients with BRVO-ME were randomly assigned to receive $4 \mathrm{mg}$ IVT monotherapy ( $n=17), 1.25 \mathrm{mg}$ IVB monotherapy $(n=14)$, or a combination of $2 \mathrm{mg}$ IVT and $1.25 \mathrm{mg}$ IVB ( $n=21)$. After one month, all groups showed significant improvement in VA and CMT. At six months, the significant reduction in the CMT was sustained while only the bevacizumab monotherapy group demonstrated significant improvement in the BCVA. Based on these results, at six months, IVB might lead to better functional outcomes compared to the other regimens in this study. Ocular side effects occurred more frequently in the 4 $\mathrm{mg}$ triamcinolone group compared to the other groups. A mean IOP increase of 1.4, -0.1, and 0.5 $\mathrm{mmHg}$ occurred in three groups, respectively. Also, cataract progression occurred $36 \%, 8 \%$, and $10 \%$ in the three study arms, respectively. ${ }^{[66]}$

In a study by Higashyama, ${ }^{[67]}$ eyes with BRVOME were randomly allocated to receive $4 \mathrm{mg}$ IVT or $1.25 \mathrm{mg}$ IVB with 12-month follow-up; additional injections were administered between 3 and 12 months if it was indicated based on the study criteria. After 12 months, the functional improvement from baseline was significantly higher in the IVB group, although no significant difference was seen in CMT reduction between the groups. Therefore, Intravitreal injection of bevacizumab may be a better treatment than that of triamcinolone acetonide for BRVO-ME. Given the three-month delay in resuming the treatment after the initial injection, under-treatment of patients should be considered in the appraisal of the results of this study.

Aflibercept. VIBRANT Study ${ }^{[68]}$ (study to Assess the Clinical Efficacy and Safety of VEGF TrapEye in Patients with BRVO) was a double-masked randomized trial that evaluated the six-month outcomes of intravitreal aflibercept versus macular laser in BRVO-ME. After six months, monthly aflibercept injection was associated with more functional and structural improvements than macular grid laser in eyes with BRVO-ME.

In the second phase of this study, after the first six months, aflibercept injection was allowed for patients primarily randomized to laser. ${ }^{[69]}$ Aflibercept was injected every eight weeks instead of every four weeks in the primary aflibercept group. It was interesting that even with the eightweek interval regimen, the functional and anatomical improvements gained with monthly injections during the initial six months of the study were maintained. In addition, the laser/aflibercept group had significant VA improvement after initiating aflibercept; however, the improvement was still significantly less than in the eyes that received aflibercept from the beginning of the study ( $P=$ 0.02 ), indicating the importance of earlier initiation of treatment. At week 52, the mean CMT reduction from baseline was -283 and $-249 \mu \mathrm{m}$ in the aflibercept and laser/aflibercept groups, respectively. In conclusion, anatomical outcome was not significantly changed even with deferral of the treatment, but maximum visual improvement which could be achieved with early aflibercept injection might not be attained in the deferral group. 


\section{Meta-analysis}

\section{Ranibizumab versus Sham Injections}

Participants. A total of 555 patients with RVO-ME were enrolled in three studies including ROCC, ${ }^{[28]}$ BRAVO, ${ }^{[56,57]}$ and CRUISE. ${ }^{29,30]}$ The baseline characteristics of participants in these trials were not significantly different concerning age, gender, and systemic factors (e.g., Ischemic heart disease, hypertension, and diabetes mellitus).

Mean Change in BCVA and CMT at Six Months. All three studies reported changes in BCVA and CMT and reported measures of dispersion (SD or 95\% Cl). At month 6 , the pooled mean change in BCVA ranged from -2 to +7.3 letters and +11 to +18.3 letters in the sham and treatment groups, respectively. The highest gain in VA was observed within two months of treatment with anti-VEGFs, with no deterioration thereafter to six months in all studies. After six months, the pooled MD between anti-VEGF and sham was 12.7 letters (95\% Cl: 11.00 to 13.2). As the statistical heterogeneity was not considerable $(12=0 \%, P=0.84)$, data was combined in the meta-analysis because the direction of effect was similar for all trials [Figure 2a]. Results showed superiority of ranibizumab compared to the sham.

The pooled mean CMT improvement at six months ranged from -117 to $-167 \mu \mathrm{m}$ and -304 to $-452 \mu \mathrm{m}$ in the sham and treatment groups, respectively. Meta-analysis of the data showed that patients who underwent ranibizumab injection had more reduction of pooled mean CMT compared with the sham group, (95\% Cl: -153 to $-284 \mu \mathrm{m})$. There was significant statistical heterogeneity (12 $=80 \%, p<0.01$ ) [Figure $2 \mathrm{~b}$ ]. Hence, we used the Random-effect model. This represents that, based on anatomical changes, anti-VEGF treatment is associated with clinically significant benefits compared with sham at six months.

\section{Bevacizumab versus Intravitreal Triamcinolone}

Participants. A total of 149 patients, with ME secondary to RVO, were enrolled in three studies (Ramezani et al, ${ }^{[21]}$ Ding et al, ${ }^{[22]}$ and Cekic ${ }^{[66]}$ et al). The baseline characteristics of participants in these trials were also similar.

Mean Change in BCVA and CMT at Six Months. All three studies reported changes in BCVA,
CMT, and measures of dispersion (SD or $95 \% \mathrm{Cl}$ ) (Ramezani et al, Ding et al, and Cekic et al). The pooled mean change in BCVA letter score at six months ranged from +9 to +48 letters and +23.5 to +32 letters in the triamcinolone and bevacizumab groups, respectively. At six months, the pooled MD between bevacizumab and triamcinolone was 5.3 letters in favor of bevacizumab (95\% Cl: -16 to 17.5$)$. The statistical heterogeneity was not considerable $(12=50.3 \%, p=0.13)$. Since the direction of effect was the same for all of the studies, we combined data in the meta-analysis [Figure 3a]. There was no significant difference in visual improvement between the two therapies.

The pooled mean reduction in CMT at six months ranged from a -75 to $-450 \mu \mathrm{m}$ and -132 to $408 \mu \mathrm{m}$ in the triamcinolone and bevacizumab groups, respectively. Meta-analysis of the data suggests that the pooled mean CMT reduction was significantly more in the triamcinolone groups compared with the bevacizumab groups during the first month, with no significant differences in macular thickness after six-months follow-up. Patients treated with triamcinolone had a pooled mean reduction in CMT of $-68.1 \mu \mathrm{m}$ more than patients treated with bevacizumab, (95\% Cl: -58 to $-76 \mu \mathrm{m})$. There was a significant statistical heterogeneity (12 $=72.1 \%, p=0.02$ ) [Figure 3b]. Therefore, Randomeffect model was used. Based on the anatomical changes, no clinically significant superiority of IVB over triamcinolone injections was observed at six months.

\section{DISCUSSION}

Many pharmaceutical agents have been used for the treatment of RVO-ME; however, three modalities including intravitreal ranibizumab, aflibercept, and dexamethasone implant are FDA approved. The functional and anatomical results of randomized controlled trials of the five most common pharmaceutical agents used in the treatment of RVO-ME are summarized in Tables 1 and 2. Almost all of them could improve the vision and reduce the macular thickness compared with sham injection or macular grid laser photocoagulation at months 6 , 12, and 24. In addition, based on seven major RCTs including BRAVO, CRUISE, HORIZON, Epstein et al, COPERNICUS, GALILEO, and VIBRANT, earlier treatment with these agents may lead to 


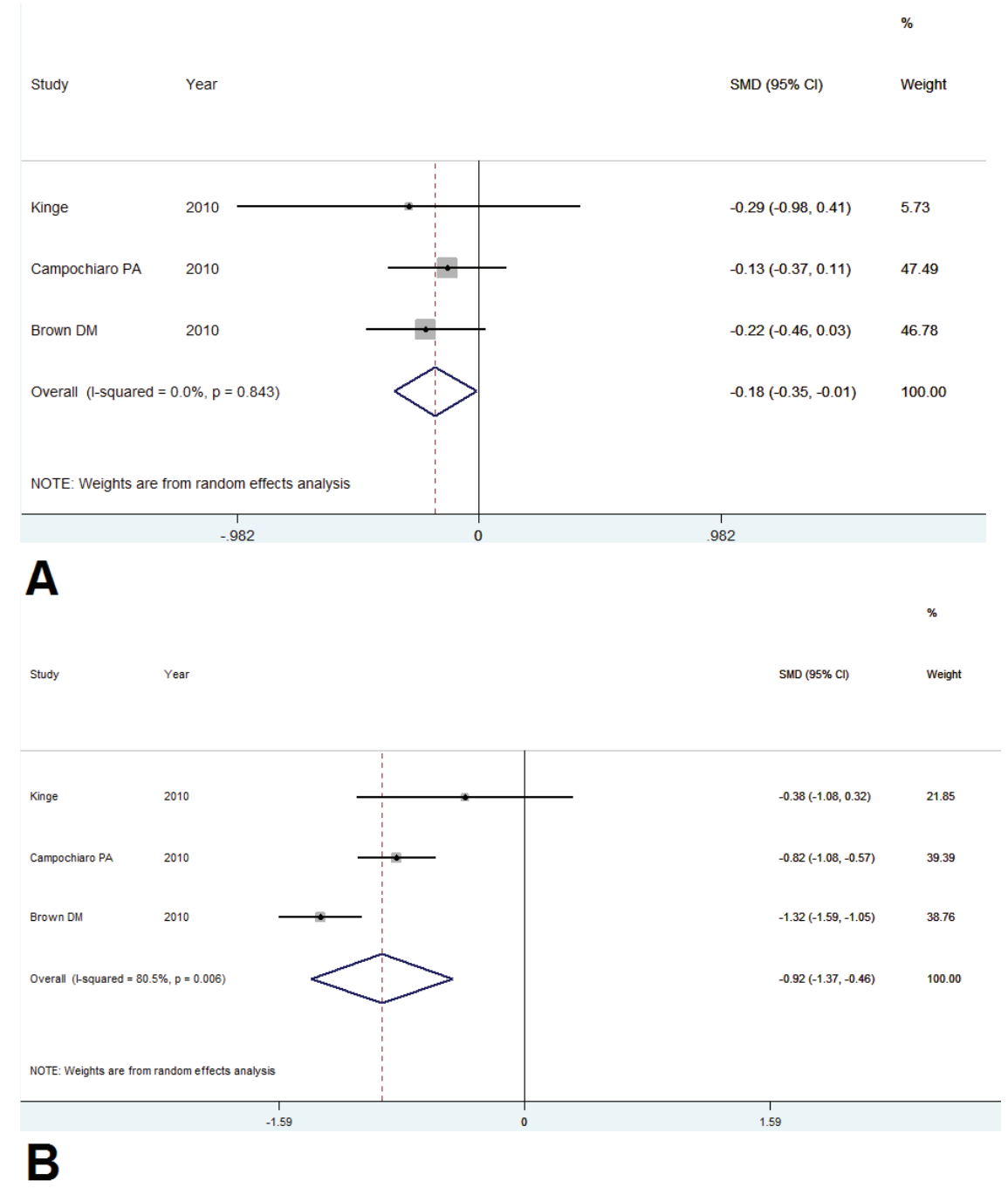

Figure 2. Forest plot displaying pooled summary estimates with ranibizumab treatment versus sham injection at 24 weeks. (a) Regarding VA, there was no significant heterogeneity $(12=0 \%, p=0.84)$. Due to small number of included studies, either fixedeffect or random-effect analysis was applied or the overall $95 \% \mathrm{Cl}$ was meaningful $(-0.35$ to -0.01$)$. (b) Regarding CMT, there was significant heterogeneity $(12=80 \%, \mathrm{p}<0.01)$, hence, the random-effect model was used and the overall $95 \% \mathrm{Cl}$ was meaningful (-1.37 to -0.46). Cl, confidence interval; CMT, central macular thickness; VA, visual acuity

better outcomes. ${ }^{[29-31,36,37,43-48,56,57,68,69]}$ Significant ocular or systemic adverse effects of antiVEGF agents are rare. Intraocular pressure rise and cataract progression mostly occurred following intravitreal corticosteroid injections.

Based on the SCORE study, ${ }^{[18]}$ the proportion of patients with CRVO gaining 15 letters of ETDRS after 12 months was $6.8 \%, 26.5 \%$, and $25.6 \%$ in the observation, $1 \mathrm{mg} \mathrm{IVT}$, and $4 \mathrm{mg}$ IVT groups, respectively. At four months, the mean reduction in CMT was greater in the $4 \mathrm{mg}$ IVT group. However, no difference was seen regarding CMT improvement among the treatment groups after 12 months. In the triamcinolone-treated patients, authors reported a reduction in ME with a moderate correlation with VA; however, there was a significantly higher percentage of patients requiring IOP-lowering medications and a higher rate of cataract development in the $4 \mathrm{mg}$ IVT group. Hence, the authors suggested $1 \mathrm{mg}$ IVT injection for ME secondary to CRVO. In eyes with BRVO, the comparison was made between intravitreal triamcinolone and laser treatment. No significant difference was found although the $4 \mathrm{mg}$ IVT group again was associated with the highest rate of adverse events. ${ }^{[18,54]}$ Comparing intravitreal triamcinolone and anti-VEGF agents, more functional improvement may occur with anti-VEGF injection 


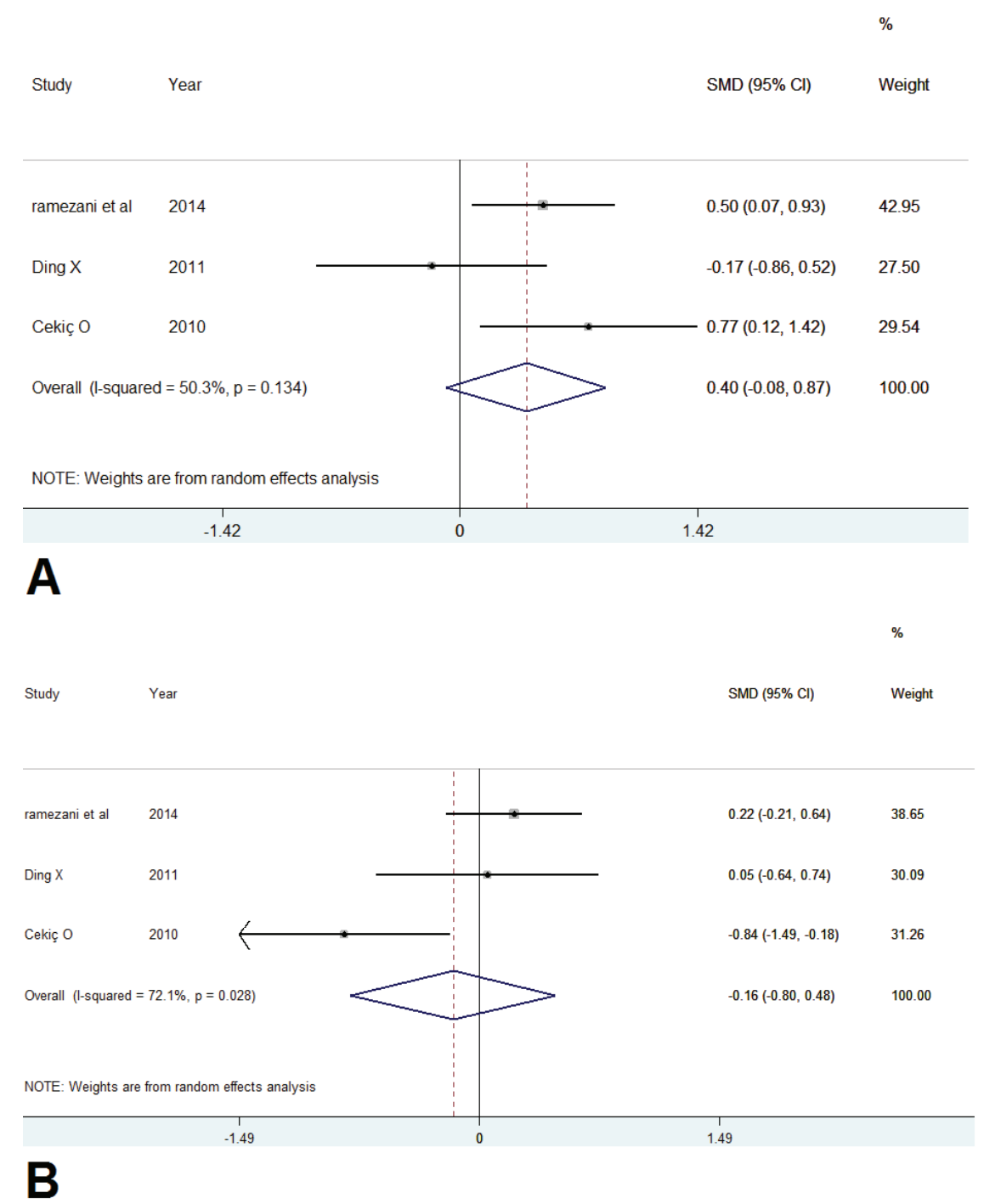

Figure 3. Forest plot displaying pooled summary estimates with bevacizumab treatment versus triamcinolone injection at 24 weeks. (a) Regarding VA, since there was no significant heterogeneity $(12=50 \%, p=0.13)$, either fixed-effect or randomeffect analysis was applied or the overall $95 \% \mathrm{Cl}$ was not meaningful (-0.08 to 0.87). (b) Regarding CMT, there was significant heterogeneity between included studies $(12=72 \%, \mathrm{p}=0.02)$ and thus, the random-effect model was used and the overall $95 \% \mathrm{Cl}$ was not meaningful (-0.80 to 0.48). $\mathrm{Cl}$, confidence interval; CMT, central macular thickness; VA, visual acuity

although triamcinolone may be accompanied with faster structural improvement. ${ }^{[21,22,66]}$

Dexamethasone implant was compared with the sham treatment in RVO eyes in the GENEVA study. ${ }^{[23,24,55]}$ After three months, both structural and functional improvements were significantly higher in eyes treated with dexamethasone implant compared to sham injection, but this effect was not maintained after six months. The maximum therapeutic effect of intravitreal dexamethasone implant is about 12 weeks after injection. Therefore, treatment repetition is necessary even with dexamethasone implantable agents. The peak response observed at three months is accompanied by the highest incidence of IOP rise and cataract formation. The therapeutic effect (both structural and functional) was greater in eyes with CRVO eyes than in eyes with BRVO.

Patient selection in the GENEVA study was not randomized for retinal ischemia; a large proportion of non-ischemic RVO patients were enrolled. Hence, the study didn't address the use of Ozurdex in ischemic CRVO patients. A post-hoc analysis showed that dexamethasone implantation earlier than three months after the BRVO occurrence 
was associated with greater VA improvement compared with the eyes with longer duration of ME. According to the COMRADE study, ${ }^{[26]}$ anti-VEGF and dexamethasone implant treatment groups had a similar outcome in the first two months, however, dexamethasone's efficacy decreased from month 3 , while ranibizumab maintained its efficacy up to month 6. It showed that dexamethasone reimplantation might be required earlier than six months. The SOLO study also reported early reinjection of dexamethasone implants in most of the cases $^{[25]}$. In the study by Guignier et al, a higher percentage of eyes with BRVO achieved 15 letters or more in the IVB group (30\%) compared with the dexamethasone group (11\%) after 6 months. ${ }^{[55]}$ Although faster functional and anatomical recovery during the first month was observed in eyes that received dexamethasone implant compared to the IVB-treated eyes, the reinjection rate at four months was also higher with dexamethasone.

In cases undergoing treatment with antiVEGF injection, various protocols have been suggested. These protocols include loading doses of three to six monthly injections, followed by re-injections on a PRN basis according to the functional and structural changes. It seems that aflibercept injection can be performed at longer intervals without a significant reduction in its efficacy. Although the "treat-and-extend" regimen is frequently applied in anti-VEGF treatment in age-related macular degeneration, this protocol has also been recently used in ME due to RVOs using aflibercept with good outomes. ${ }^{[51]}$ All trials showed that repeated anti-VEGF injection was associated with significant improvement in the functional outcomes at six months compared to the placebo. The functional improvement was also accompanied by favorable structural outcomes. $^{[18,23,24,29,30,36,37,43-48,50,54,56,57,68,69]}$

The impact of treatment delay was evaluated in some studies including VIBRANT, ${ }^{[68,69]}$ COPERNICUS, ${ }^{[43-45]}$ EPSTEIN ${ }^{[36,37]}$ and GALILEO. ${ }^{[47,48,64]}$ These RCTs suggested that a shorter interval between the diagnosis and the treatment of RVO-ME was associated with the greatest benefit of anti-VEGFs. The extension of main studies on anti-VEGFs in which the control group received sham injections for six months and then were switched to PRN regimen between months 7 and 12, further confirmed this evidence. Postponing anti-VEGGF therapy for six months could still have a good structural outcome with no significant difference between the treatment groups at month 12 . In contrast, while functional outcomes improved with switching to PRN antiVEGF injections after six months in the sham group, these outcomes remained significantly lower at one year compared with the groups treated with anti-VEGF agents from the outset (COPERNICUS, ${ }^{[43-45]}$ CRUISE, ${ }^{[29,30]}$ and Epstein et al $\left.^{[36,37]}\right)$.

In the HORIZON ${ }^{[31]}$ study (the 24-month extension of CRUISE and BRAVO studies), visual outcomes, but not macular thickness, worsened in the second year of treatment especially in the CRVO arm. This may be due to the reduced efficacy of anti-VEGFs during the treatment course. The other reason may be lower treatment frequency from months 12 to 24, especially in patients with CRVO. As we know, the non-perfusion area of retina is usually larger in CRVO than in BRVO, and this causes a higher concentration of VEGF. ${ }^{[7]}$ Therefore, more intravitreal injections may be needed in the second year of treatment of eyes with CRVOME than those with BRVO-ME. Regarding iris or retinal neovascularisation or neovascular glaucoma, anti-VEGF therapy led to a significant reduction of neovascular complications compared to the sham treatment at six months (COPERNICUS, ${ }^{\text {[43-45] }}$ CRUISE, ${ }^{29,30]}$ Epstein et al, ${ }^{[36,37]}$ GALILEO, ${ }^{[46-48]}$ ROCC, ${ }^{[28]}$ and VIBRANT ${ }^{[68,69]}$ ). In eyes treated with aflibercept, the visual and anatomical improvements that occurred within the first 24 weeks of the study with monthly $2 \mathrm{mg}$ dosing were maintained with bimonthly dosing.

\section{Comparison of Studies with Different Treatment Modalities}

A direct comparison between CRUISE (ranibizumab) and COPERNICUS/GALILEO (aflibercept), GENEVA (dexamethasone), SCORE

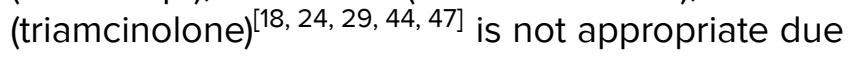
to several key differences in the study designs, protocols, and population. For instance, eyes with more severity of ischemia (e.g., the presence of an RAPD) and more chronic disease were not enrolled in the BRAVO study but were allowed in SCORE. Hence, it is not surprising to see better results in BRAVO study. Also, longer follow-up periods in the SCORE might have led to under-treatment. Likewise, in the GENEVA study, in the first six 
months of the study, only a single treatment with dexamethasone implant was allowed, probably resulting in the under-treatment as the implant's peak effect is at two to three months.

In the CRUISE ${ }^{[29,30]}$ trial, patients with sustained ME of more than 12 months or an RAPD were excluded, while prior treatment with anti-VEGF therapy was not defined as an exclusion criteria. In contrast, in COPERNICUS/GALILEO ${ }^{[43-48]}$ trials, patients were specifically excluded if they had sustained ME of more than nine-months duration or prior anti-VEGF treatment, and the presence of an RAPD was not mentioned in the exclusion criteria. ${ }^{[70,71]}$

It is also not possible to compare the results between CRUISE and SCORE as CRUISE study might have included healthier eyes compared with SCORE; in CRUISE trial (but not in SCORE), patients were excluded if they had ME for more than 12 months or an RAPD (probably indicating extensive capillary dropout and ischemia); follow-up and retreatment in CRUISE was monthly, but it was implemented every four months in the SCORE. Therefore, direct comparison of these studies may lead to a misjudgment. ${ }^{\text {[70] }}$

Almost all trials reported that the greatest reduction in CMT occurred within a month of the first injection. Also, the CMT improvement was sustained during the treatment period. However, this is in contrary to the observed course of CMT changes in the control groups, who demonstrated a smoother and linear reduction in CMT over the time.

In this study, meta-analysis showed that treatment with ranibizumab was associated with more anatomical and functional improvement compared to the sham after six months, while there was no significant difference in anatomical and visual outcomes between bevacizumab and triamcinolone after six months. Although inclusion criteria for meta-analysis was narrowed to permit including comparable studies with similar arms, it should be noted that some variables (i.e., the time needed to wait before starting the treatment) were not matched and could be a potential source of bias.

\section{SUMMARY}

This systematic review and the meta-analysis demonstrates that treatment with anti-VEGFs provides significant structural and functional gains compared to the observation in eyes with RVO. There was no significant difference between eyes treated with bevacizumab and intravitreal corticosteroid based on this meta-analysis. However, it seems that repeated anti-VEGF injections, especially for ischemic cases, may be accompanied with better visual outcomes and fewer side effects in the long term.

\section{Financial Support and Sponsorship}

Nil.

\section{Conflicts of Interest}

There are no conflicts of interest.

\section{REFERENCES}

1. Green WR, Chan CC, Hutchins GM, Terry JM. Central retinal vein occlusion: a prospective histopathologic study of 29 eyes in 28 cases. Retina 1981;1:27-55.

2. Bertelsen $M$, Linneberg A, Christoffersen $N$, Vorum $H$, Gade E, Larsen M. Mortality in patients with central retinal vein occlusion. Ophthalmology 2014;121:637-642.

3. Elman MJ, Bhatt AK, Quinlan PM, Enger C. The risk for systemic vascular diseases and mortality in patients with central retinal vein occlusion. Ophthalmology 1990;97:15431548.

4. Dodson PM, Galton DJ, Hamilton AM, Blach RK. Retinal vein occlusion and the prevalence of lipoprotein abnormalities. Br J Ophthalmol 1982;66:161-164.

5. Koizumi H, Ferrara DC, Brue C, Spaide RF. Central retinal vein occlusion case-control study. Am J Ophthalmol 2007;144:858-863.

6. Wang $Y X$, Zhang JS, You QS, Xu L, Jonas JB. Ocular diseases and 10-year mortality: the Beijing Eye Study 2001/2011. Acta Ophthalmol 2014;92:e424-e428.

7. Hayreh SS. Ocular vascular occlusive disorders: natural history of visual outcome. Prog Retin Eye Res 2014;41:1-25.

8. Glacet-Bernard A, Coscas G, Chabanel A, Zourdani A, Lelong F, Samama MM. Prognostic factors for retinal vein occlusion: prospective study of 175 cases. Ophthalmology 1996;103:551-560.

9. Argon laser photocoagulation for macular edema in branch vein occlusion. The branch vein occlusion study group. Am J Ophthalmol 1984;98:271-282.

10. Varma R, Bressler NM, Suner I, Lee P, Dolan CM, Ward J, et al. Improved vision-related function after ranibizumab for macular edema after retinal vein occlusion: results from the BRAVO and CRUISE trials. Ophthalmology 2012;119:21082118.

11. Hayreh SS, Podhajsky PA, Zimmerman MB. Branch retinal artery occlusion: natural history of visual outcome. Ophthalmology 2009;116:1188-1194.e1-e4. 
12. Oxford Centre for Evidence-Based Medicine. Levels of evidence; 2009 [cited January 31, 2017.]. Available from: http://www.cebm.net/index. aspx?0.1025.

13. Crowther M, Lim W, Crowther MA. Systematic review and meta-analysis methodology. Blood 2010;116:3140-3146.

14. Moher D, Liberati A, Tetzlaff J, Altman DG, The PG. Preferred reporting items for systematic reviews and meta-analyses: the PRISMA statement. PLOS Med 2009;6:e1000097.

15. Ip MS, Gottlieb JL, Kahana A, Scott IU, Altaweel MM, Blodi $\mathrm{BA}$, et al. Intravitreal triamcinolone for the treatment of macular edema associated with central retinal vein occlusion. Arch Ophthalmol (Chicago, III : 1960) 2004;122:11311136.

16. Braithwaite T, Nanji AA, Lindsley K, Greenberg PB. Antivascular endothelial growth factor for macular oedema secondary to central retinal vein occlusion. Cochrane Database Syst Rev 2014:Cd007325.

17. Mohamed Q, Mclntosh RL, Saw SM, Wong TY. Interventions for central retinal vein occlusion: an evidence-based systematic review. Ophthalmology 2007;114:507-519, 524.

18. Ip MS, Scott IU, VanVeldhuisen PC, Oden NL, Blodi BA, Fisher $\mathrm{M}$, et al. A randomized trial comparing the efficacy and safety of intravitreal triamcinolone with observation to treat vision loss associated with macular edema secondary to central retinal vein occlusion: the Standard Care vs Corticosteroid for Retinal Vein Occlusion (SCORE) study report 5. Arch Ophthalmol (Chicago, III : 1960) 2009;127:1101-1114.

19. Jonas JB, Degenring RF, Kamppeter BA, Kreissig I, Akkoyun I. Duration of the effect of intravitreal triamcinolone acetonide as treatment for diffuse diabetic macular edema. Am J Ophthalmol 2004;138:158-160.

20. Jonas JB, Jonas RA, Neumaier M, Findeisen P. Cytokine concentration in aqueous humor of eyes with diabetic macular edema. Retina 2012;32:2150-2157.

21. Ramezani A, Esfandiari H, Entezari M, Moradian S, Soheilian M, Dehsarvi B, et al. Three intravitreal bevacizumab versus two intravitreal triamcinolone injections in recent onset central retinal vein occlusion. Acta Ophthalmol 2014;92:e530-e539.

22. Ding X, Li J, Hu X, Yu S, Pan J, Tang S. Prospective study of intravitreal triamcinolone acetonide versus bevacizumab for macular edema secondary to central retinal vein occlusion. Retina 2011;31:838-845.

23. Haller JA, Bandello F, Belfort R, Jr., Blumenkranz MS, Gillies M, Heier J, et al. Randomized, sham-controlled trial of dexamethasone intravitreal implant in patients with macular edema due to retinal vein occlusion. Ophthalmology 2010;117:1134-1146.e3.

24. Haller JA, Bandello F, Belfort R, Jr., Blumenkranz MS, Gillies M, Heier J, et al. Dexamethasone intravitreal implant in patients with macular edema related to branch or central retinal vein occlusion twelve-month study results. Ophthalmology 2011;118:2453-2460.

25. Bezatis A, Spital G, Hohn F, Maier M, Clemens CR, Wachtlin $\mathrm{J}$, et al. Functional and anatomical results after a single intravitreal Ozurdex injection in retinal vein occlusion: a 6-month follow-up - the SOLO study. Acta Ophthalmol 2013;91:e340-e347.

26. Hoerauf H, Feltgen N, Weiss C, Paulus EM, SchmitzValckenberg S, Pielen A, et al. Clinical efficacy and safety of ranibizumab versus dexamethasone for central retinal vein occlusion (COMRADE C): a European label study. Am J Ophthalmol 2016;169:258-267.

27. Gado AS, Macky TA. Dexamethasone intravitreous implant versus bevacizumab for central retinal vein occlusionrelated macular oedema: a prospective randomized comparison. Clin Exp Ophthalmol 2014;42:650-655.

28. Kinge B, Stordahl PB, Forsaa V, Fossen K, Haugstad M, Helgesen $\mathrm{OH}$, et al. Efficacy of ranibizumab in patients with macular edema secondary to central retinal vein occlusion: results from the sham-controlled ROCC study. Am J Ophthalmol 2010;150:310-314.

29. Brown DM, Campochiaro PA, Singh RP, Li Z, Gray S, Saroj $\mathrm{N}$, et al. Ranibizumab for macular edema following central retinal vein occlusion: six-month primary end point results of a phase III study. Ophthalmology 2010;117:1124-1133.e1.

30. Campochiaro PA, Brown DM, Awh CC, Lee SY, Gray S, Saroj N, et al. Sustained benefits from ranibizumab for macular edema following central retinal vein occlusion: twelve-month outcomes of a phase III study. Ophthalmo/ogy 2011;118:2041-2049.

31. Heier JS, Campochiaro PA, Yau L, Li Z, Saroj N, Rubio $R G$, et al. Ranibizumab for macular edema due to retinal vein occlusions: long-term follow-up in the HORIZON trial. Ophthalmology 2012;119:802-809.

32. Thach AB, Yau L, Hoang C, Tuomi L. Time to clinically significant visual acuity gains after ranibizumab treatment for retinal vein occlusion: BRAVO and CRUISE trials. Ophthalmology 2014;121:1059-1066.

33. Kriechbaum K, Michels S, Prager F, Georgopoulos M, Funk M, Geitzenauer W, et al. Intravitreal Avastin for macular oedema secondary to retinal vein occlusion: a prospective study. Br J Ophthalmol 2008;92:518.

34. Prager F, Michels S, Kriechbaum K, Georgopoulos M, Funk M, Geitzenauer W, et al. Intravitreal bevacizumab (Avastin) for macular oedema secondary to retinal vein occlusion: 12-month results of a prospective clinical trial. Br J Ophthalmol 2009;93:452-456.

35. Zhang H, Liu Z-L, Sun P, Gu F. Intravitreal bevacizumab for treatment of macular edema secondary to central retinal vein occlusion: eighteen-month results of a prospective trial. J Ocul Pharmacol Ther 2011;27:615-621.

36. Epstein DL, Algvere PV, von Wendt G, Seregard S, Kvanta A. Bevacizumab for macular edema in central retinal vein occlusion: a prospective, randomized, double-masked clinical study. Ophthalmology 2012;119:1184-1189.

37. Epstein DL, Algvere PV, von Wendt G, Seregard S, Kvanta A. Benefit from bevacizumab for macular edema in central retinal vein occlusion: twelve-month results of a prospective, randomized study. Ophthalmology 2012;119:25872591.

38. Rajagopal R, Shah GK, Blinder KJ, Altaweel M, Eliott D, Wee $R$, et al. Bevacizumab versus ranibizumab in the treatment of macular edema due to retinal vein occlusion: 6-month results of the CRAVE study. Ophthalmic Surg Lasers Imaging Retina 2015;46:844-850.

39. Costa RA, Jorge R, Calucci D, Melo LA, Jr., Cardillo JA, Scott IU. Intravitreal bevacizumab (avastin) for central and hemicentral retinal vein occlusions: IBeVO study. Retina 2007;27:141-149. 
40. Ferrara DC, Koizumi H, Spaide RF. Early bevacizumab treatment of central retinal vein occlusion. Am J Ophthalmol 2007;144:864-871.

41. Pai SA, Shetty R, Vijayan PB, Venkatasubramaniam G, Yadav NK, Shetty BK, et al. Clinical, anatomic, and electrophysiologic evaluation following intravitreal bevacizumab for macular edema in retinal vein occlusion. Am J Ophthalmol 2007;143:601-606.

42. Mayer WJ, Remy M, Wolf A, Kook D, Kampik A, Ulbig $M$, et al. Comparison of intravitreal bevacizumab upload followed by a dexamethasone implant versus dexamethasone implant monotherapy for retinal vein occlusion with macular edema. Ophthalmologica 2012;228:110-116.

43. Boyer D, Heier J, Brown DM, Clark WL, Vitti R, Berliner AJ, et al. Vascular endothelial growth factor Trap-Eye for macular edema secondary to central retinal vein occlusion: six-month results of the phase 3 COPERNICUS study. Ophthalmology 2012;119:1024-1032.

44. Brown DM, Heier JS, Clark WL, Boyer DS, Vitti R, Berliner $A J$, et al. Intravitreal aflibercept injection for macular edema secondary to central retinal vein occlusion: 1year results from the phase 3 COPERNICUS study. Am $J$ Ophthalmol 2013;155:429-437.e7.

45. Heier JS, Clark WL, Boyer DS, Brown DM, Vitti R, Berliner $A J$, et al. Intravitreal aflibercept injection for macular edema due to central retinal vein occlusion: two-year results from the COPERNICUS study. Ophthalmology 2014;121:1414-1420.e1.

46. Holz FG, Roider J, Ogura Y, Korobelnik JF, Simader C, Groetzbach G, et al. VEGF Trap-Eye for macular oedema secondary to central retinal vein occlusion: 6-month results of the phase III GALILEO study. $\mathrm{Br} J$ Ophthalmol 2013;97:278-284.

47. Korobelnik JF, Holz FG, Roider J, Ogura Y, Simader C, Schmidt-Erfurth $U$, et al. Intravitreal aflibercept injection for macular edema resulting from central retinal vein occlusion: one-year results of the phase 3 GALILEO study. Ophthalmology 2014;121:202-208.

48. Ogura Y, Roider J, Korobelnik JF, Holz FG, Simader C, Schmidt-Erfurth $U$, et al. Intravitreal aflibercept for macular edema secondary to central retinal vein occlusion: 18month results of the phase 3 GALILEO study. Am J Ophthalmol 2014;158:1032-1038.

49. Saishin $Y$, Ito $Y$, Fujikawa M, Sawada T, Ohji M. Comparison between ranibizumab and aflibercept for macular edema associated with central retinal vein occlusion. Jpn J Ophthalmol 2017;61:67-73.

50. Scott IU, VanVeldhuisen PC, Ip MS, Blodi BA, Oden NL, Awh CC, et al. Effect of bevacizumab vs aflibercept on visual acuity among patients with macular edema due to central retinal vein occlusion: the SCORE2 randomized clinical trial. JAMA 2017;317:2072-2087.

51. Casselholm de Salles M, Amren U, Kvanta A, Epstein DL. Injection frequency of aflibercept versus ranibizumab in a treat-and-extend regimen for central retinal vein occlusion: a randomized clinical trial. Retina 2019;39:1370-1376.

52. Bavbek T, Yenice O, Toygar O. Problems with attempted chorioretinal venous anastomosis by laser for nonischemic CRVO and BRVO. Ophthalmologica 2005;219:267-271.

53. Raszewska-Steglinska $M$, Gozdek P, Cisiecki S, Michalewska Z, Michalewski J, Nawrocki J. Pars plana vitrectomy with ILM peeling for macular edema secondary to retinal vein occlusion. Eur J Ophthalmol 2009;19:10551062.

54. Scott IU, Ip MS, VanVeldhuisen PC, Oden NL, Blodi BA, Fisher $\mathrm{M}$, et al. A randomized trial comparing the efficacy and safety of intravitreal triamcinolone with standard care to treat vision loss associated with macular Edema secondary to branch retinal vein occlusion: the Standard Care vs Corticosteroid for Retinal Vein Occlusion (SCORE) study report 6. Arch Ophthalmol (Chicago, III : 1960) 2009;127:1115-1128.

55. Guignier B, Subilia-Guignier A, Fournier I, Ballonzoli L, Speeg-Schatz C, Gaucher D. Prospective pilot study: efficacy of intravitreal dexamethasone and bevacizumab injections in the treatment of macular oedema associated with branch retinal vein occlusion. Ophthalmologica 2013;230:43-9.

56. Campochiaro PA, Heier JS, Feiner L, Gray S, Saroj N, Rundle $\mathrm{AC}$, et al. Ranibizumab for macular edema following branch retinal vein occlusion: six-month primary end point results of a phase III study. Ophthalmology 2010;117:11021112.e1.

57. Brown DM, Campochiaro PA, Bhisitkul RB, Ho AC, Gray $\mathrm{S}$, Saroj N, et al. Sustained benefits from ranibizumab for macular edema following branch retinal vein occlusion: 12-month outcomes of a phase III study. Ophthalmology 2011;118:1594-1602.

58. Tadayoni R, Waldstein SM, Boscia F, Gerding H, Pearce I, Priglinger $\mathrm{S}$, et al. Individualized stabilization criteriadriven ranibizumab versus laser in branch retinal vein occlusion: six-month results of BRIGHTER. Ophthalmology 2016;123:1332-1344.

59. Tan MH, McAllister IL, Gillies ME, Verma N, Banerjee $G$, Smithies LA, et al. Randomized controlled trial of intravitreal ranibizumab versus standard grid laser for macular edema following branch retinal vein occlusion. Am J Ophthalmol 2014;157:237-247.e1.

60. Pielen A, Mirshahi A, Feltgen N, Lorenz K, Korb C, Junker $B$, et al. Ranibizumab for Branch Retinal Vein Occlusion Associated Macular Edema Study (RABAMES): six-month results of a prospective randomized clinical trial. Acta Ophthalmol 2015;93:e29-e37.

61. Ehlers JP, Decroos FC, Fekrat S. Intravitreal bevacizumab for macular edema secondary to branch retinal vein occlusion. Retina 2011;31:1856-1862.

62. Moradian S, Faghihi H, Sadeghi B, Piri N, Ahmadieh $H$, Soheilian $M$, et al. Intravitreal bevacizumab vs. sham treatment in acute branch retinal vein occlusion with macular edema: results at 3 months (Report 1). Graefe Arch Clin Exp Ophthalmol 2011;249:193-200.

63. Russo V, Barone A, Conte E, Prascina F, Stella A, Noci ND. Bevacizumab compared with macular laser grid photocoagulation for cystoid macular edema in branch retinal vein occlusion. Retina 2009;29:511-515.

64. Parodi MB, lacono P, Bandello F. Subthreshold grid laser versus intravitreal bevacizumab as second-line therapy for macular edema in branch retinal vein occlusion recurring after conventional grid laser treatment. Graefe Arch Clin Exp Ophthalmol 2015;253:1647-1651.

65. Narayanan R, Panchal B, Das T, Chhablani J, Jalali S, Ali $\mathrm{MH}$. A randomised, double-masked, controlled study of the efficacy and safety of intravitreal bevacizumab versus ranibizumab in the treatment of macular oedema due to 
branch retinal vein occlusion: MARVEL Report No. 1. Br J Ophthalmol 2015;99:954-959.

66. Cekic O, Cakir M, Yazici AT, Alagoz N, Bozkurt E, Faruk Yilmaz O. A comparison of three different intravitreal treatment modalities of macular edema due to branch retinal vein occlusion. Curr Eye Res 2010;35:925-929.

67. Higashiyama T, Sawada O, Kakinoki M, Sawada T, Kawamura $\mathrm{H}$, Ohji $\mathrm{M}$. Prospective comparisons of intravitreal injections of triamcinolone acetonide and bevacizumab for macular oedema due to branch retinal vein occlusion. Acta Ophthalmol 2013;91:318-324.

68. Campochiaro PA, Clark WL, Boyer DS, Heier JS, Brown $\mathrm{DM}$, Vitti $\mathrm{R}$, et al. Intravitreal aflibercept for macular edema following branch retinal vein occlusion: the 24week results of the VIBRANT study. Ophthalmology
2015;122:538-544.

69. Clark WL, Boyer DS, Heier JS, Brown DM, Haller JA, Vitti $R$, et al. Intravitreal aflibercept for macular edema following branch retinal vein occlusion: 52-week results of the VIBRANT study. Ophthalmology 2016;123:330-336.

70. Ehlers JP, Kim SJ, Yeh S, Thorne JE, Mruthyunjaya P, Schoenberger SD, et al. Therapies for macular edema associated with branch retinal vein occlusion: a report by the American Academy of Ophthalmology. Ophthalmology 2017;124:1412-1423.

71. Zacharias LC, Lin T, Migon R, Ghosn C, Orilla W, Feldmann $B$, et al. Assessment of the differences in pharmacokinetics and pharmacodynamics between four distinct formulations of triamcinolone acetonide. Retina 2013;33:522-531. 